Supporting Information to

\title{
Electrochemiluminescence Self-Interference Spectroscopy with Vertical Nanoscale Resolution
}

Yafeng Wang, Weiliang Guo, Qian Yang and Bin Su*

Institute of Analytical Chemistry, Department of Chemistry, Zhejiang University, Hangzhou 310058, China

\author{
${ }^{*}$ Corresponding Authors: Prof. Bin Su \\ Email: subin@zju.edu.cn
}

\section{Table of Contents}

S1. Experimental Details $\quad$ S-2

S2. Theory - Matrix Propagation Model S-7

S3. ECLI - Luminophore Monolayer $\quad$ S-14

S4. ECLI - Solution Phase $\quad$ S-19

S5. MATLAB Code for Calculation $\quad$ S-23

$\begin{array}{lr}\text { References } & \text { S-30 }\end{array}$ 


\section{S1. Experimental Details}

\section{S1.1. Chemicals and Reagents}

All chemicals and reagents were used as received without further purification. All aqueous solutions were prepared with ultrapure water $(18.2 \mathrm{M} \Omega \mathrm{cm})$. Acetonitrile, ethanol, acetone, diethyl ether, dichloromethane, $\mathrm{KCl}, \mathrm{KNO}_{3}, \mathrm{NaCl}, \mathrm{NaOH}, \mathrm{Na}_{2} \mathrm{HPO}_{4}$, $\mathrm{NaH}_{2} \mathrm{PO}_{4}$, concentrated $\mathrm{H}_{2} \mathrm{SO}_{4}(95-98 \%)$, concentrated $\mathrm{HCl}(36-38 \%), \mathrm{H}_{2} \mathrm{O}_{2}(30 \%)$ and hydrazine hydrate $\left(\mathrm{N}_{2} \mathrm{H}_{4} \cdot x \mathrm{H}_{2} \mathrm{O}, 50 \%\right)$ were bought from Sinopharm. Sodium pyruvate, $\mathrm{MgCl}_{2}, \mathrm{KPF}_{6}$, ammonium acetate $\left(\mathrm{NH}_{4} \mathrm{OAc}\right)$, 4-nitrobenzaldehyde, EDTA, activated charcoal, $10 \% \mathrm{Pd} / \mathrm{C}$, celite, ethyl acetate, tris(hydroxymethyl)aminomethane (Tris), trin-propylamine (TPrA) and 2-(dibutylamino)ethanol (DBAE) were purchased from Aladdin. 1-Ethyl-3-(3-(dimethylamino)propyl)carbodiimide hydrochloride (EDC), Nhydroxysuccinimide (NHS), 3-mercaptopropionic acid (MPA), cis-dichlorobis(2,2'bipyridine)ruthenium(II) (cis- $\left.\mathrm{Ru}(\mathrm{bpy}){ }_{2} \mathrm{Cl}_{2} \cdot 2 \mathrm{H}_{2} \mathrm{O}\right), 6$-mercapto-1-hexanol and 1-[2-oxo2-(2-pyridinyl)ethyl]pyridinium iodide were obtained from J\&K Scientific.

The labeled oligonucleotides were synthesized by Sangon Biotech (Shanghai, China), purified by HPLC and confirmed by mass spectrometry. The double strand DNA consisting of fifty base pairs ( $50 \mathrm{bp}$ dsDNA) is composed of two single strands: 5'-Ru-CATGCCTGCAGGTCGACTCTAGAGGATCCCCGGGTACCGAGCTCGAATTC-3' $5 '-\mathrm{SH}-\left(\mathrm{CH}_{2}\right)_{6}$

-GAATTCGAGCTCGGTACCCGGGGATCCTCTAGAGTCGACCTGCAGGCATG-3'

4-(4-Aminophenyl)-2,2'-bipyridine (apbpy) was synthesized as reported in the literature. ${ }^{\mathrm{S} 1}$ Scheme S1a illustrates the synthetic procedure. ${ }^{1} \mathrm{H} \mathrm{NMR}\left(400 \mathrm{MHz}, \mathrm{CDCl}_{3}\right)$ $\delta 8.72(\mathrm{ddd}, J=4.8,1.8,0.9 \mathrm{~Hz}, 1 \mathrm{H}), 8.66(\mathrm{~d}, J=5.3 \mathrm{~Hz}, 1 \mathrm{H}), 8.64(\mathrm{~d}, J=1.8 \mathrm{~Hz}, 1 \mathrm{H})$, $8.48(\mathrm{~d}, J=8.0 \mathrm{~Hz}, 1 \mathrm{H}), 7.85(\mathrm{td}, J=7.8,1.8 \mathrm{~Hz}, 1 \mathrm{H}), 7.65(\mathrm{~d}, J=8.7 \mathrm{~Hz}, 2 \mathrm{H}), 7.52(\mathrm{dd}, J$ $=5.3,1.9 \mathrm{~Hz}, 1 \mathrm{H}$ ), 7.34 (ddd, $J=7.5,4.8,1.2 \mathrm{~Hz}, 1 \mathrm{H}), 6.79(\mathrm{~d}, J=8.7 \mathrm{~Hz}, 2 \mathrm{H})$.

$\mathrm{Ru}(\mathrm{bpy})_{2}(\mathrm{apbpy})\left(\mathrm{PF}_{6}\right)_{2}$ was also synthesized as reported previously, ${ }^{52-3}$ and the synthetic procedure is illustrated in Scheme S1b. cis- $\mathrm{Ru}(\mathrm{bpy}){ }_{2} \mathrm{Cl}_{2} \cdot 2 \mathrm{H}_{2} \mathrm{O}(317 \mathrm{mg}, 0.61$ $\mathrm{mmol}$ ) and apbpy (150 mg, $0.61 \mathrm{mmol})$ were dissolved in a mixture of EtOH $(20 \mathrm{~mL})$ 
and water $(20 \mathrm{~mL})$. The mixture was refluxed at $85^{\circ} \mathrm{C}$ for $18 \mathrm{~h}$ under the $\mathrm{N}_{2}$ atmosphere. After cooling down to room temperature, ethanol was removed under reduced pressure. Saturated aqueous $\mathrm{KPF}_{6}$ solution was added to the residue. The resulting precipitate was collected by filtration and washed with $\mathrm{H}_{2} \mathrm{O}$ and ether. The crude material was purified by flash chromatography on silica gel (eluent: saturated aqueous $\left.\mathrm{KNO}_{3} / \mathrm{H}_{2} \mathrm{O} / \mathrm{CH}_{3} \mathrm{CN}, 1 / 4 / 40\right)$. After purification, the obtained solid was dissolved in ethanol solution, and then dropped in the $\mathrm{KPF}_{6}$ saturated solution. The resulting precipitate was collected by filtration, and thoroughly washed with $\mathrm{H}_{2} \mathrm{O}$ and ether. A red solid (500 mg, 86\%) was obtained. ${ }^{1} \mathrm{H}$ NMR (400 MHz, DMSO-d6) $\delta 9.10$ (d, J = 8.3 $\mathrm{Hz}, 1 \mathrm{H}), 8.95(\mathrm{~s}, 1 \mathrm{H}), 8.84(\mathrm{~d}, J=8.3 \mathrm{~Hz}, 4 \mathrm{H}), 8.17(\mathrm{td}, J=7.9,1.5 \mathrm{~Hz}, 5 \mathrm{H}), 7.89-7.67$ $(m, 8 H), 7.60-7.44(m, 6 H), 6.69(d, J=8.7 \mathrm{~Hz}, 2 H), 5.86(s, 2 H)$.

a<smiles>CC(=O)C(=O)OCC(=O)OCC(=O)O</smiles><smiles>O=C(O)/C=C/c1ccc([N+](=O)[O-])cc1</smiles><smiles></smiles><smiles>Nc1ccc(-c2ccnc(-c3ccccn3)c2)cc1</smiles>

b<smiles>Nc1ccc(-c2ccnc(-c3ccccn3)c2)cc1</smiles>

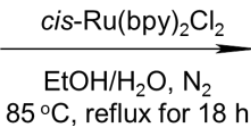<smiles></smiles>

Scheme S1. Synthetic procedures of apbpy (a) and Ru(bpy $)_{2}(a p b p y)\left(P F_{6}\right)_{2}(b)$. 


\section{S1.2. Electrochemistry, ECL and Optical Interference Measurements}

Cyclic voltammetry (CV) was performed on $\mathrm{CHI} 440 \mathrm{~A}$ electrochemical workstation (Chenhua, China) in a traditional three-electrode configuration. The gold electrode, platinum wire and $\mathrm{Ag} / \mathrm{AgCl}$ electrode (saturated $\mathrm{KCl}$ ) acted as working, counter and reference electrode, respectively. Synchronous acquisition of ECL intensity-voltage curves overlaid with CVs was accomplished on MPI-E ECL analytical system (Remex Instrument, China).
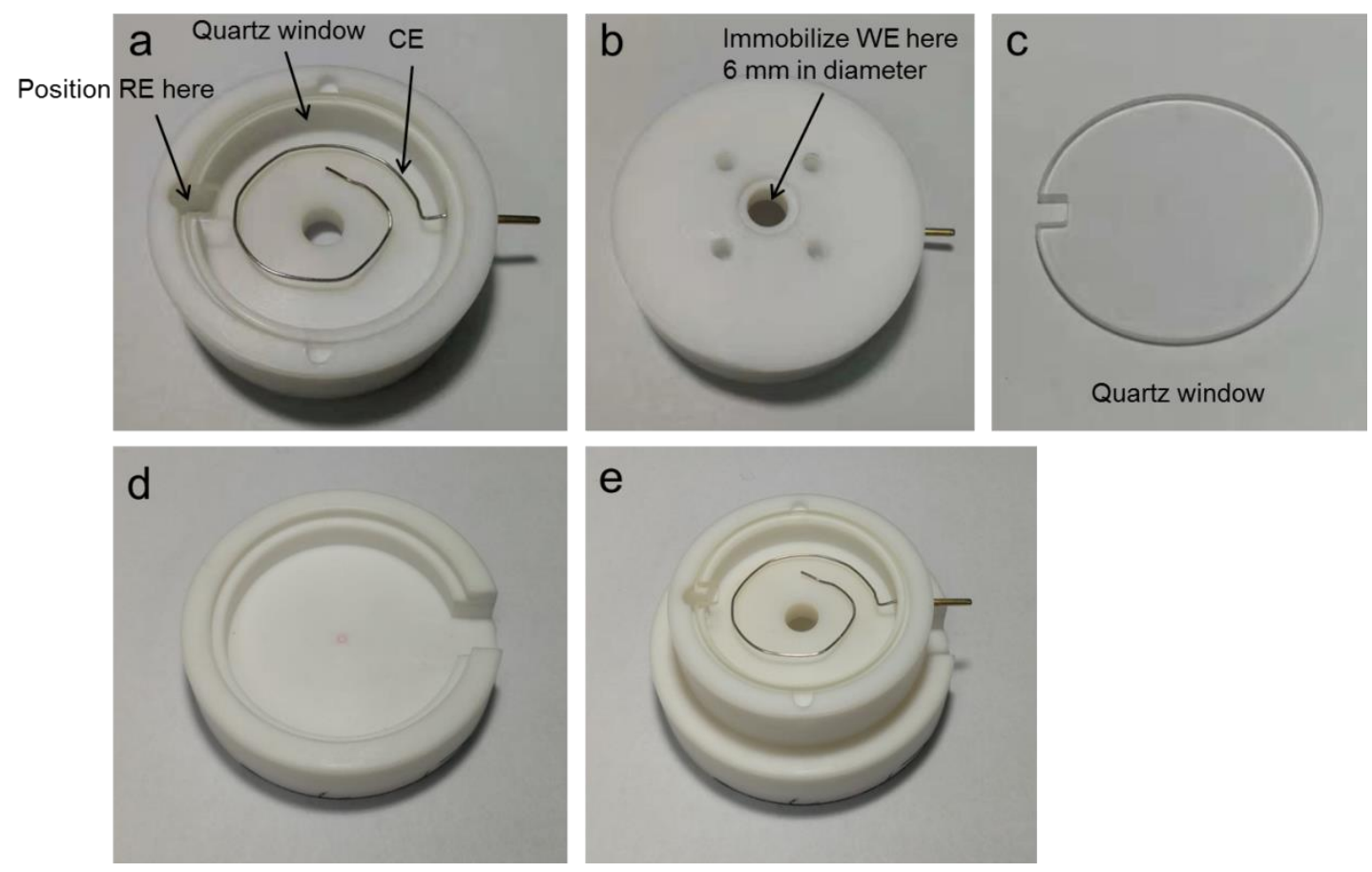

Figure S1. Photographs of the electrochemical cell used for ECLI measurements: Top-view of main body (a), bottom-view of main body (b), quartz window (c), bottom support plate (d) and the assembled cell (e).

Interferometric spectra were recorded by an optical fiber CCD-array miniature spectrometer (QEpro, Ocean Optics). In the case of white light interferometry, the white light from tungsten lamp (HL-2000-LL, Ocean Optics) was projected to the surface at normal incidence by an optical fiber (diameter $0.4 \mathrm{~mm}$, length $2 \mathrm{~m}$ ). While ECL self-interference (ECLI) spectra were recorded under dark conditions without external light incidence. The diameter and length of optical fiber used for ECLI are 1 $\mathrm{mm}$ and $1 \mathrm{~m}$, respectively. The white light reflected by electrode interfaces (or ECL 
directly emitted and that reflected by electrode interfaces) was focused by collimating lens ( $5 \mathrm{~mm}$ in diameter) to optical fiber and collected by spectrometer. The collimating lens was connected to optical fiber and vertically placed above the working electrode with a distance of ca. $18 \mathrm{~mm}$ to collect the interference light. A 200- $\mu \mathrm{m}$-wide slit was used before spectrometer for further filtering out light that is not in the vertical direction. The slit is fixed on the spectrometer and its width is invariable. The spectral integration time of ECLI for immobilized luminophores was $0.5 \mathrm{~s}$. And that for solution phase luminophores was $0.5 \mathrm{~s}\left(1 \mathrm{mM} \mathrm{Ru}(\mathrm{bpy})_{3}{ }^{2+}\right)$ and $2 \mathrm{~s}\left(1 \mu \mathrm{M} \mathrm{Ru}(\mathrm{bpy})_{3}{ }^{2+}\right)$, respectively. A custom-made round Teflon cell consisting of three elements, as shown in Figure S1, namely main body (Figure S1a, b), bottom support plate (Figure S1d) and top quartz window (Figure S1c), was used. The gold electrode was fixed on the bottom of main body with the aid of four screws and a rubber O-ring.

\section{S1.3. Fabrication and Characterization of Gold Electrodes}

p-Type silicon wafers $(100)$ coated with silica $\left(\mathrm{SiO}_{2} / \mathrm{Si}\right)$ were purchased from Resemi. Glass substrate was obtained from Kaivo. Prior to use, the wafers and glass substrates were cleaned under ultrasonication in acetone, ethanol and water sequentially for 20 min, followed by drying with $\mathrm{N}_{2}$ stream. Electron-beam evaporation of ultrathin layer of gold was performed on Denton Vacuum Explorer-14 Coating System using titanium as the adhesion. The deposition thickness was set at $3 \mathrm{~nm}$ and $10 \mathrm{~nm}$, respectively, for the titanium and gold layer. $\mathrm{SiO}_{2} / \mathrm{Si}$ wafers and glass substrates coated with gold are designated as $\mathrm{Au} / \mathrm{SiO}_{2} / \mathrm{Si}$ and $\mathrm{Au} /$ glass electrodes, respectively.

The cross-sectional morphology of electrodes was studied by scanning electron microscopy (SEM, SU8010 field-emission scanning electron microscope with an operating voltage of $5.0 \mathrm{kV}$ ). The thickness of $\mathrm{SiO}_{2}$ layer was measured by both SEM and white light interference. The thickness of evaporated titanium and gold layers was measured by ellipsometry (UVISEL Spectroscopic Ellipsometer), which was $4.65 \mathrm{~nm}$ and $11.80 \mathrm{~nm}$, respectively. The wavelength-dependent refractive indices of the gold, 
titanium, silica layers and silicon substrate were all measured by ellipsometry. As determined by atomic force microscopy (AFM, Bruker Dimension Icon), the surface roughness of $\mathrm{SiO}_{2} / \mathrm{Si}$ wafer and $\mathrm{Au} / \mathrm{SiO}_{2} / \mathrm{Si}$ electrode is less than $1 \mathrm{~nm}$ (see Figure S2).
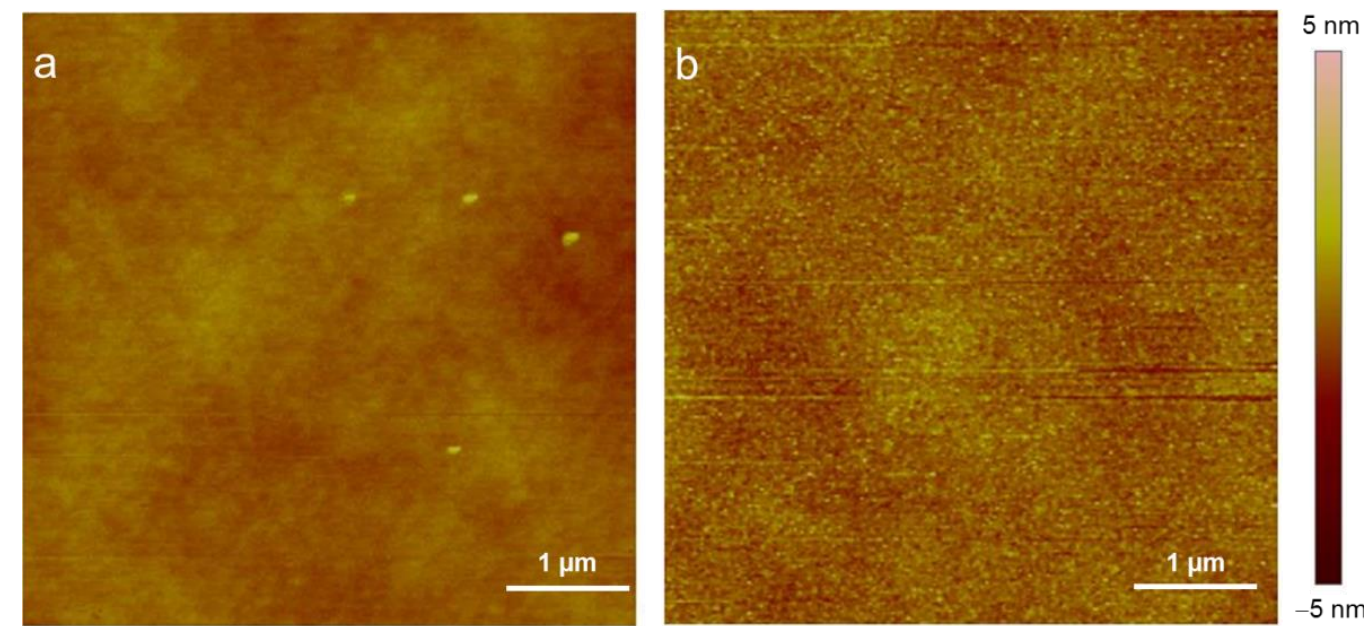

Figure S2. AFM images of $\mathrm{SiO}_{2} / \mathrm{Si}(\mathrm{a})$ and $\mathrm{Au} / \mathrm{SiO}_{2} / \mathrm{Si}$ electrode (b). 


\section{S2. Theory - Matrix Propagation Model}

\section{S2.1. Thin-Film White Light Interference}

First of all, the white light interference in air at the substrate with a thin coating film is considered (as shown in Figure S3), which is the simplest interference model. A light beam with an incident angle of $\theta_{1}$ is reflected at the air/film interface to generated beam 1. Meanwhile, the incident light is refracted to enter the film, reflected at the film/substrate interface and refracted again at the air/film interface to generate reflected beam 2 . Two reflected beams are coherent as they are from the same source. The superposition of two beams thus generates interference.

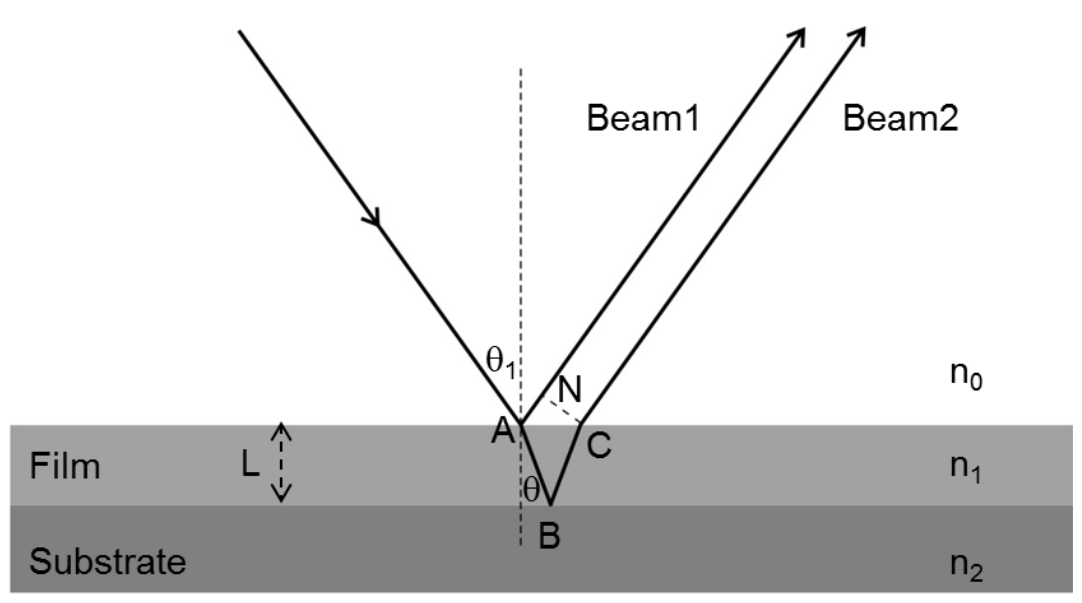

Figure S3. Schematic illustration of thin-film white light interference.

The shape of interferometric spectrum or the position of interferometric fringes mainly depends on the phase difference (PD, $\Delta \varphi$ ) or optical path difference (OPD, $\Delta S$ ) between two reflected beams. The relationship between PD and OPD can be expressed as,

$$
\Delta \varphi=2 \pi \frac{\Delta S}{\lambda}
$$

where $\lambda$ is the light wavelength. Optical path refers to the product of the distance that the beam travels and the refractive index of the medium. According to the geometric structure illustrated in Figure S3, the OPD between two reflected beams is given by, 


$$
\Delta S=n_{1}(A B+B C)-n_{0} A N
$$

where $n_{0}$ and $n_{1}$ are refractive indices of air and film, respectively. Further considering the following geometric relationships and the Snell's law (refraction law),

$$
\begin{aligned}
& A B=B C=\frac{L}{\cos \theta} \\
& A N=A C \sin \theta_{1}=2 L \tan \theta \sin \theta_{1} \\
& n_{0} \sin \theta_{1}=n_{1} \sin \theta
\end{aligned}
$$

where $\theta$ and $\theta_{1}$ are the light refraction and incident angles at the air/film interface, respectively. $L$ is the film thickness. Then, eq. $\mathbf{S 2}$ can be rewritten as,

$$
\Delta S=2 n_{1} L \cos \theta
$$

If considering only normal incidence where $\theta=\theta_{1}=0$, we will have,

$$
\Delta S=2 n_{1} L
$$

The light waves of two reflected beams can be expressed as,

$$
\begin{aligned}
& E_{1}=A_{1} \exp \left[\mathrm{i}\left(\omega_{1} t+\delta_{1}\right)\right] \\
& E_{2}=A_{2} \exp \left[\mathrm{i}\left(\omega_{2} t+\delta_{2}\right)\right]
\end{aligned}
$$

where $E, A, \omega$ and $\delta$ are the electric field strength, amplitude, angular frequency, initial phase of the beam, respectively. And the electric field strength of the interferometric wave generated by the superposition of two beams is given by,

$$
E=E_{1}+E_{2}=A_{1} \exp \left[\mathrm{i}\left(\omega_{1} t+\delta_{1}\right)\right]+A_{2} \exp \left[\mathrm{i}\left(\omega_{2} t+\delta_{2}\right)\right]
$$

The intensity of interferometric light can be written as,

$$
\begin{aligned}
I=E^{2}=\{ & \left.A_{1} \exp \left[\mathrm{i}\left(\omega_{1} t+\delta_{1}\right)\right]+A_{2} \exp \left[\mathrm{i}\left(\omega_{2} t+\delta_{2}\right)\right]\right\} \times \\
& \left\{A_{1} \exp \left[\mathrm{i}\left(\omega_{1} t+\delta_{1}\right)\right]+A_{2} \exp \left[\mathrm{i}\left(\omega_{2} t+\delta_{2}\right)\right]\right\}^{*} \\
= & A_{1}^{2}+A_{2}^{2}+2 A_{1} A_{2} \cos \left[\left(\omega_{2}-\omega_{1}\right) t+\delta_{2}-\delta_{1}\right]
\end{aligned}
$$

Since two beams are from the same source $\left(\omega_{1}=\omega_{2}\right)$, eq. $\mathbf{S 8}$ can be simplified as,

$$
I(\lambda)=A_{1}^{2}+A_{2}^{2}+2 A_{1} A_{2} \cos \left(\delta_{2}-\delta_{1}\right)
$$


where the difference value, $\delta_{2}-\delta_{1}$, represents the phase difference between two beams (namely $\Delta \varphi$ expressed by eq. $\mathbf{S 1}$ ).

Further combining eqs. S1, S5 and S9, we have,

$$
\begin{aligned}
I(\lambda) & =A_{1}^{2}+A_{2}^{2}+2 A_{1} A_{2} \cos (\Delta \varphi) \\
& =A_{1}^{2}+A_{2}^{2}+2 A_{1} A_{2} \cos \left(\frac{4 \pi n_{1} L}{\lambda}\right)
\end{aligned}
$$

Eq. S10 is used usually for calculating two-beam interference. In terms of eq. S10, the intensity of interferometric light changes periodically with the light wavelength, if the thickness $(L)$ and the refractive index of the film $\left(n_{1}\right)$ is constant. And the light intensity will reache maxima and minima when $\Delta \varphi=2 m \pi$ and $\Delta \varphi=(2 m+1) \pi$ (where $m$ has an integral value), corresponding to the constructive (peak) and destructive (valley) fringes in the spectrum. In this case, we also have,

$$
\begin{aligned}
& m \lambda=2 n_{1} L \\
& \left(m+\frac{1}{2}\right) \lambda=2 n_{1} L
\end{aligned}
$$

Eq. S11 indicates that, when the value of $2 n_{1} L$ is equal to the integral multiple of $\lambda$ or $\lambda / 2$, the light intensity will reach maxima and minima, respectively. In other words, the wavelengths at the interferometric peaks shift with $n_{1}$ and/or $L$. This relationship forms the basis of interferometric spectrum analysis, with which from the experimentally measured interferometric spectrum we can calculate $n_{1}$ and $L$.

On the other hand, in terms of eq. S10, the closer the intensity of two light beams (represented by the values of $A_{1}$ and $A_{2}$ ) is, the stronger the interferometric peaks will be in the spectrum. At the $\mathrm{SiO}_{2} / \mathrm{Si}$ substrate, the intensities of light reflected from the $\mathrm{SiO}_{2}$ surface and the $\mathrm{SiO}_{2} / \mathrm{Si}$ interface are comparable. While at the $\mathrm{Au} / \mathrm{SiO} 2 / \mathrm{Si}$ electrode, the intensity of light reflected from the gold surface is higher than that from bottom interfaces, given the gold surface has a higher light reflectance. This explains qualitatively why the interferometric peaks at the $\mathrm{SiO}_{2} / \mathrm{Si}$ substrate are sharper and stronger than those at the $\mathrm{Au} / \mathrm{SiO}_{2} / \mathrm{Si}$ electrode (see Figure $\mathbf{2 c}, \mathbf{d}$ ). 


\section{S2.2. Matrix Propagation Model}

Above description only considers light reflection at two interfaces. Practical light reflection in the film, even in a single layer film, is much more complicated involving multiple reflection inside the film. In order to take these multiple reflections into account to consider more precisely the travel and optical path difference of light, the matrix propagation model can be used. ${ }^{S 4}$ Note that the discussion below is based on normal incidence, which is reasonable for white light interference and ECLI in this study. As for oblique incidence, details are shown in ref S4. Figure S4 illustrates the simplification of single layer film (such as the $\mathrm{SiO}_{2} / \mathrm{Si}$ wafer) consisting of two reflection interfaces and multilayer film (such as the $\mathrm{Au} / \mathrm{SiO}_{2} / \mathrm{Si}$ electrode) consisting of $q$ layers and multiple reflection interfaces to a single front interface. In this case, the problem becomes merely calculating the optical property, such as reflectance, of a simple interface between an incident medium and an assembly consisted of the films and substrate.

a

\begin{tabular}{ll} 
Incident medium & $n_{0}$ \\
\hline Film & $n_{1}$ \\
\hline Substrate & $n_{\mathrm{s}}$ \\
\hline \multicolumn{2}{c}{ Single layer film }
\end{tabular}

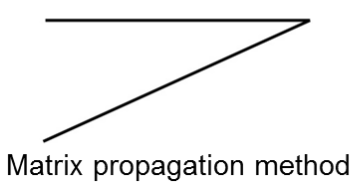

Incident medium

Assembly of films

and substrate

b

\begin{tabular}{lc} 
Incident medium & $n_{0}$ \\
\hline Film 1 & $n_{1}$ \\
\hline Film 2 & $n_{2}$ \\
\hline Film 3 & $n_{3}$ \\
\hline & $\cdots$ \\
\hline Film q & $n_{\mathrm{q}}$ \\
\hline Substrate & $n_{\mathrm{s}}$ \\
\hline \multicolumn{2}{c}{ Multilayer film }
\end{tabular}

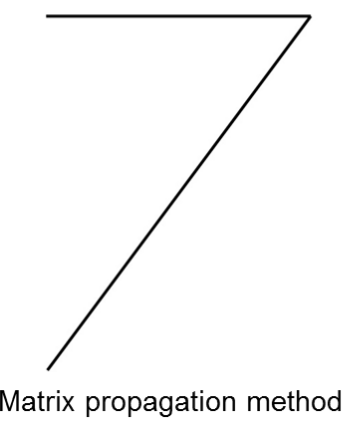

Incident medium
$\begin{aligned} & \text { Assembly of films } \\ & \text { and substrate }\end{aligned}$

Figure S4. Schematic illustration of matrix propagation model for single layer film (a) and multilayer film (b). The refractive indices of each layers are noted in the graph. 
The characteristic matrix for the thin film can be expressed by a $2 \times 2$ matrix,

$$
\left[\begin{array}{l}
B \\
C
\end{array}\right]=\left\{\prod_{r=1}^{q}\left[\begin{array}{cc}
\cos \delta_{\mathrm{r}} & \left(\mathrm{i} \sin \delta_{\mathrm{r}}\right) / n_{\mathrm{r}} \\
\mathrm{i} n_{\mathrm{r}} \sin \delta_{\mathrm{r}} & \cos \delta_{\mathrm{r}}
\end{array}\right]\right\}\left[\begin{array}{c}
1 \\
n_{\mathrm{s}}
\end{array}\right]
$$

where $B$ and $C$ are the normalized electric and magnetic fields at the front interface, respectively, from which we can extract properties of the thin film system. $\delta_{r}=2 \pi n_{r} L_{r} / \lambda$, and $n_{r}, L_{r}$ are the refractive index and thickness of the $q$ layer, respectively. $n_{s}$ is the refractive index of the substrate. From eq. S12, we can readily calculate the reflectance of the film $(R)$ by,

$$
R=\left(\frac{n_{0} B-C}{n_{0} B+C}\right)\left(\frac{n_{0} B-C}{n_{0} B+C}\right)^{*}
$$

where $n_{0}$ is the refractive index of incident medium.

And the phase difference $\left(\Delta \varphi_{R}\right)$ due to reflection at the front interface is given by,

$$
\Delta \varphi_{\mathrm{R}}=\arctan \left[\frac{\mathrm{i} n_{0}\left(C B^{*}-B C^{*}\right)}{n_{0}{ }^{2} B B^{*}-C C^{*}}\right]
$$

Note that eq. $\mathbf{S 1 4}$ cannot be directly substituted to eq. $\mathbf{S 1 0}$ to calculate the intensity of the interference light, because eq. S14 expresses the phase difference of light caused by reflection at the multilayer film involving multiple beams. Eq. S10 is only suitable for two-beam interference.

Furthermore, if the film is a light absorbing medium (such as gold, titanium and silicon), its refractive index $(n)$ should be replaced by the complex refractive index $(N)$,

$$
N=n-i k
$$

where $k$ is the extinction coefficient. 


\section{S2.3. Calculation of White Light Interferometric Spectra}

The shape of interferometric spectrum depends primarily on the envelope of light source and the film reflectance. In the case of white light interference, the former can be easily obtained by measuring the spectrum of white light source. The latter can be calculated by matrix propagation model (eq. S13). Then the interferometric spectrum can be calculated as the product of envelope of light source (namely intensity of the incident light, $I_{0}$ ) and the film reflectance (eq. S13) under different wavelengths,

$$
I(\lambda)=I_{0}(\lambda) R
$$

According to eq. S11, a thicker film (namely a larger $L$ ) will result in more peaks in the spectrum (as shown in Figure S5). While for the film with a fixed thickness, the shape of interferometric spectra will be dominated by the envelope of light source (Figure S6).

When calculating the interferometric spectra, for both $\mathrm{SiO}_{2} / \mathrm{Si}$ substrate and $\mathrm{Au} / \mathrm{SiO}_{2} / \mathrm{Si}$ electrode, only the thickness of $\mathrm{SiO}_{2}$ layer was a variable. In the case of latter electrode, the thickness of gold layer and titanium layers determined by ellipsometry were directly used. The calculations were done by MATLAB software. Using a minimum of least-squares deviation as the criterion, the optimal matching between calculated and experimental spectra gave us the thickness of $\mathrm{SiO}_{2}$ layer (the same in the following for the analysis of ECLI spectra). 


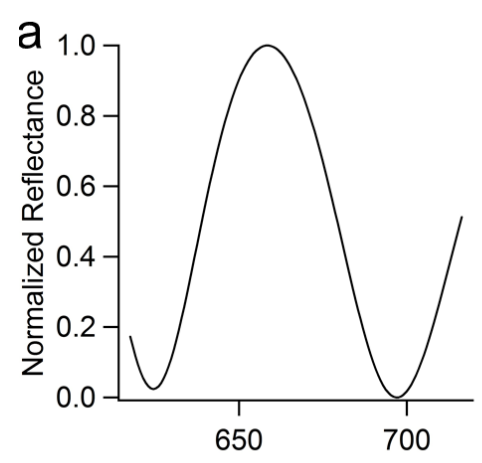

Wavelength / nm

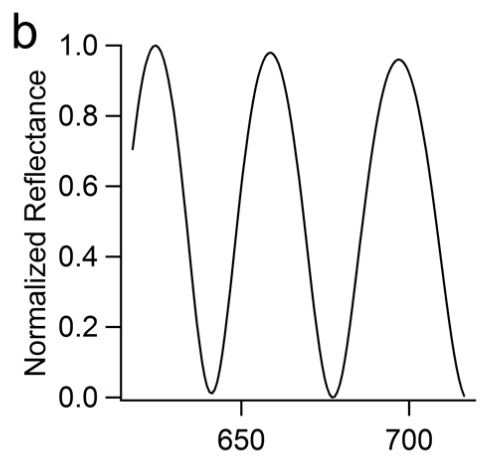

Wavelength / nm

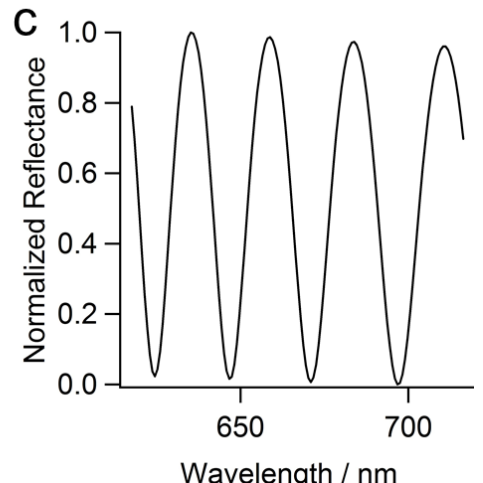

Wavelength / $\mathrm{nm}$

Figure S5. Normalized reflectance spectra in air calculated by matrix propagation model for the $\mathrm{SiO}_{2} / \mathrm{Si}$ substrate with different thickness of $\mathrm{SiO}_{2}$ layer: $2 \mu \mathrm{m}$ (a), $4 \mu \mathrm{m}$ (b) and $6 \mu \mathrm{m}$ (c).

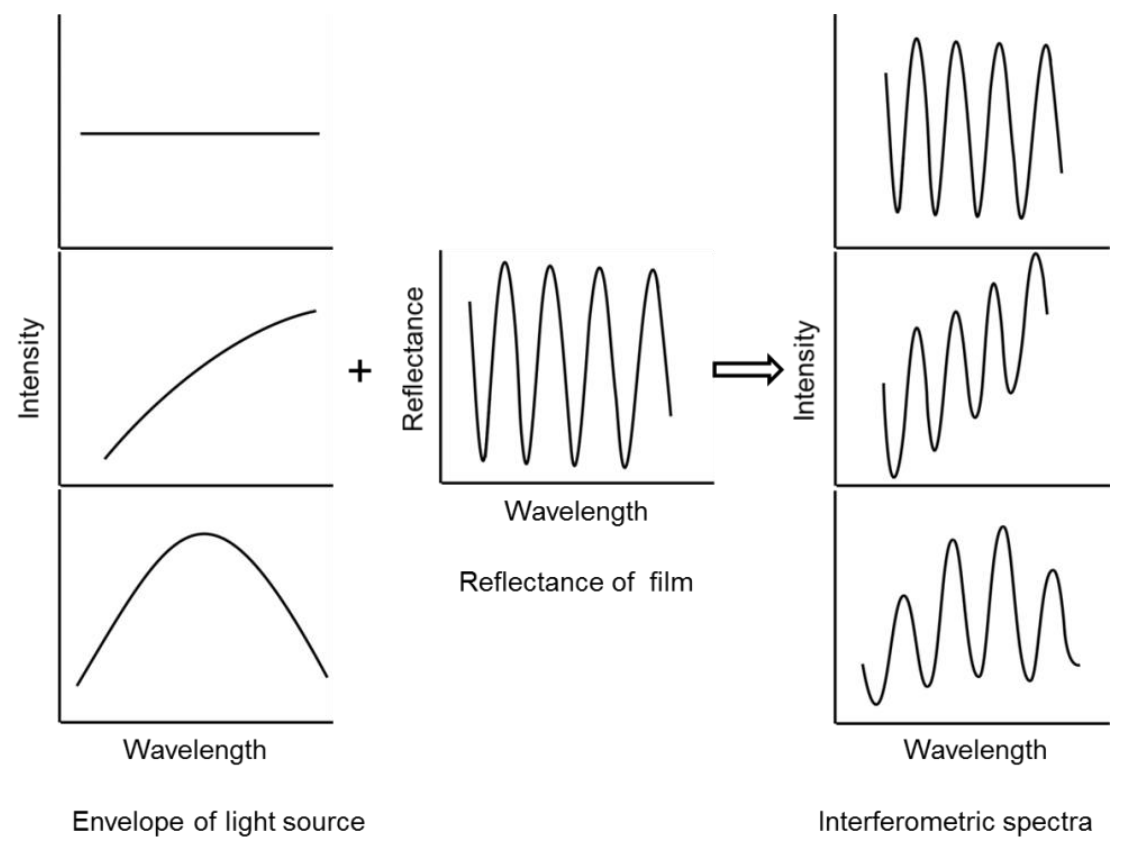

Figure S6. Effect of the envelope of light source on the shape of interferometric spectra. 


\section{S3. ECLI - Luminophore Monolayer}

\section{S3.1. Preparation of Luminophore Monolayer on Gold Electrodes}

The $\mathrm{Au} / \mathrm{SiO}_{2} / \mathrm{Si}$ electrode was first cleaned in freshly prepared piranha solution (7:3 v/v mixture of concentrated $\mathrm{H}_{2} \mathrm{SO}_{4}$ and $30 \% \mathrm{H}_{2} \mathrm{O}_{2}$ ) at $90{ }^{\circ} \mathrm{C}$ for 3 min and then rinsed thoroughly with water. Caution: Piranha solution is very dangerous. It can react violently with organic materials, and should be handled very carefully.

To prepare MPA-bridged luminophore monolayer, the cleaned electrode was immersed in $1 \mathrm{mM}$ MPA ethanol solution. After $18 \mathrm{~h}$, the electrode surface was rinsed with ethanol and water, and dried with $\mathrm{N}_{2}$. Then, the electrode was immersed in 50 $\mathrm{mM}$ PB solution ( $\mathrm{pH}$ 7.4) containing $5 \mathrm{mM}$ EDC and $5 \mathrm{mM} \mathrm{NHS}$ for 40 min under magnetic stirring. After rinsing with water, it was immersed in a 9:1 mixture of PB (50 $\mathrm{mM}, \mathrm{pH} 7.4) / \mathrm{CH}_{3} \mathrm{CN}$ containing $0.5 \mathrm{mM} \mathrm{Ru}(\mathrm{bpy})_{2}(\mathrm{apbpy})\left(\mathrm{PF}_{6}\right)_{2}$ for $60 \mathrm{~min}$ under magnetic stirring. Finally, the electrode was rinsed with ethanol and water, and dried with $\mathrm{N}_{2}$. Figure S7a shows the ECL intensity-voltage curve overlaid with cyclic voltammogram (CV), proving the successful immobilization of luminophores for $E C L$ generation. For comparison, the monolayer film was also prepared on the Au/glass electrode, which only gave rise to normal ECL spectrum with a single peak (Figure S7b, the spectrum is not smooth because of low ECL intensity).
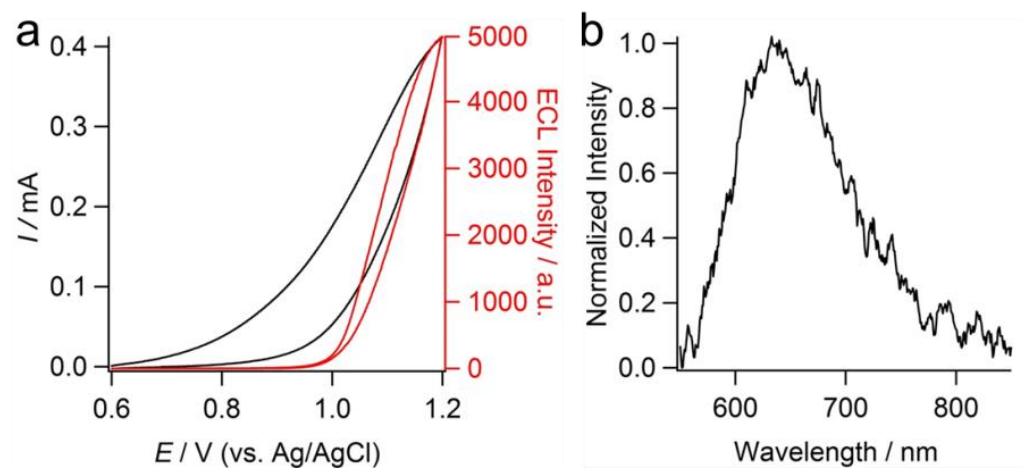

Figure S7. (a) ECL intensity-potential curve overlaid with CV for MPA-bridged monolayer on the $\mathrm{Au} / \mathrm{SiO}_{2} / \mathrm{Si}$ electrode. (b) ECL spectrum recorded for MPA-bridged monolayer on the $\mathrm{Au} / \mathrm{glass}$ electrode. The measurements were performed in $\mathrm{PB}$ solution $(0.2 \mathrm{M}, \mathrm{pH}$ 7.4) containing $30 \mathrm{mM}$ DBAE. Scan rate: $0.05 \mathrm{~V} / \mathrm{s}$. PMT voltage: $550 \mathrm{~V}$. 
To prepare dsDNA-bridged luminophore monolayer, dsDNA was firstly prepared by heating equimolar amounts of single-strand $\mathrm{Ru}(\mathrm{bpy}) 3^{2+}$-modified (DNA-1) and thiolmodified DNA (DNA-2) in Tris buffer (10 mM Tris, $50 \mathrm{mM} \mathrm{NaCl}, 1 \mathrm{mM}$ EDTA, $\mathrm{pH}$ 8) at $95{ }^{\circ} \mathrm{C}$ for $2 \mathrm{~min}$ and subsequently cooling down to room temperature slowly. The $\mathrm{Au} / \mathrm{SiO}_{2} / \mathrm{Si}$ or $\mathrm{Au} / \mathrm{glass}$ electrode was modified by spreading a droplet of $25 \mu \mathrm{L}$ of Tris buffer containing $7 \mu \mathrm{M}$ dsDNA on its surface. Then, the modified electrode was stored in a humid environment at $4{ }^{\circ} \mathrm{C}$, and after $24 \mathrm{~h}$ it was rinsed with water and incubated in $10 \mathrm{mM}$ 6-mercaptohexanol ethanol solution overnight at room temperature. Finally, the electrode was rinsed with water and dried with $N_{2}$. Figure S8a shows the ECL intensity-voltage curve overlaid with CV, proving the successful immobilization of luminophores for ECL generation. For comparison, the monolayer film was also prepared on the Au/glass electrode, which gave rise to normal ECL spectrum with a single peak (Figure $\mathbf{S 8 b}$, the spectrum is not smooth because of low ECL intensity).
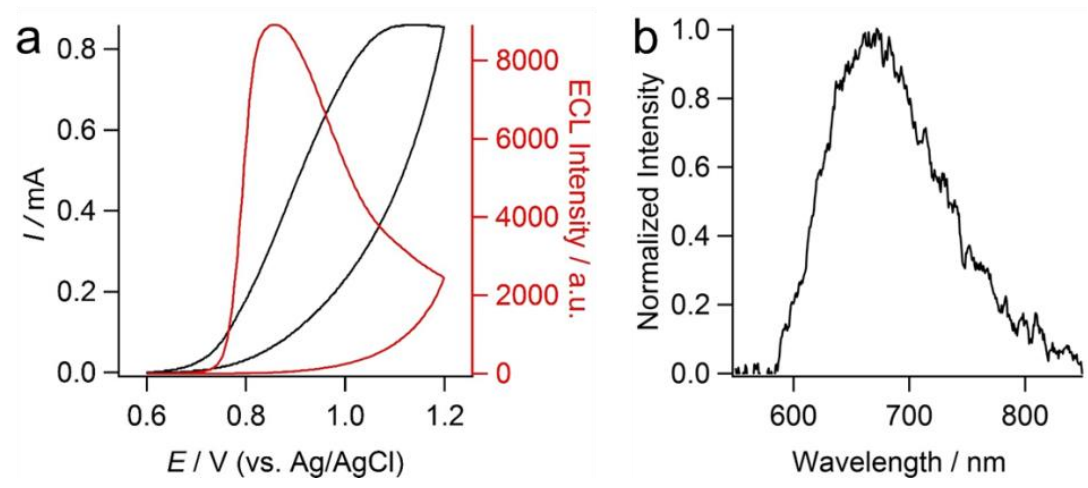

Figure S8. (a) ECL intensity-potential curve overlaid with CV for dsDNA-bridged monolayer on the $\mathrm{Au} / \mathrm{SiO}_{2} / \mathrm{Si}$ electrode. (b) ECL spectrum recorded for dsDNA-bridged monolayer on the $\mathrm{Au} / \mathrm{glass}$ electrode. The measurements were performed in PB solution $(0.2 \mathrm{M}, \mathrm{pH}$ 7.4) containing $30 \mathrm{mM}$ DBAE. Scan rate: $0.05 \mathrm{~V} / \mathrm{s}$. PMT voltage: $550 \mathrm{~V}$.

\section{S3.2. Calculation by Matrix Propagation Model}

As shown in Figure S9, ECLI arises from the superposition of two ECL beams generated by luminophores, namely directly emitted beam and that reflected by the film electrode. The reflection of $\mathrm{ECL}$ by the $\mathrm{Au} / \mathrm{SiO}_{2} / \mathrm{Si}$ film electrode can be also treated by 
matrix propagation model, being equivalent to light reflection at a single front interface. In this case, ECLI can be simply considered as two-beam interference. The phase difference between ECL directly emitted by luminophores and that reflected at the single reflection interface consists of the extra optical path that the reflected beam travels (the extra path is twice of the height of ECL luminophore at the electrode surface, eq. S1) and the phase difference caused by reflection at the front interface (eq. S14). Given the intensity of ECL emitted by luminophores in all directions is equal, the intensity of direct ECL beam $\left(I_{1}(\lambda)\right)$ and that reflected by the front interface $\left(I_{2}(\lambda)\right)$ have the following relationship,

$$
I_{2}(\lambda)=I_{1}(\lambda) R
$$

Further considering that the light intensity is proportional to the square of light amplitude $\left(/ \propto A^{2}\right)$, eq. $\mathbf{S 1 0}$ can be rewritten as,

$$
\frac{I(\lambda)}{I_{1}(\lambda)}=1+R+2 \sqrt{R} \cos (\Delta \varphi)
$$

Eq. S18 thus allows the calculation of ECLI spectrum. The right side of eq. S18 represents the interferometric components.

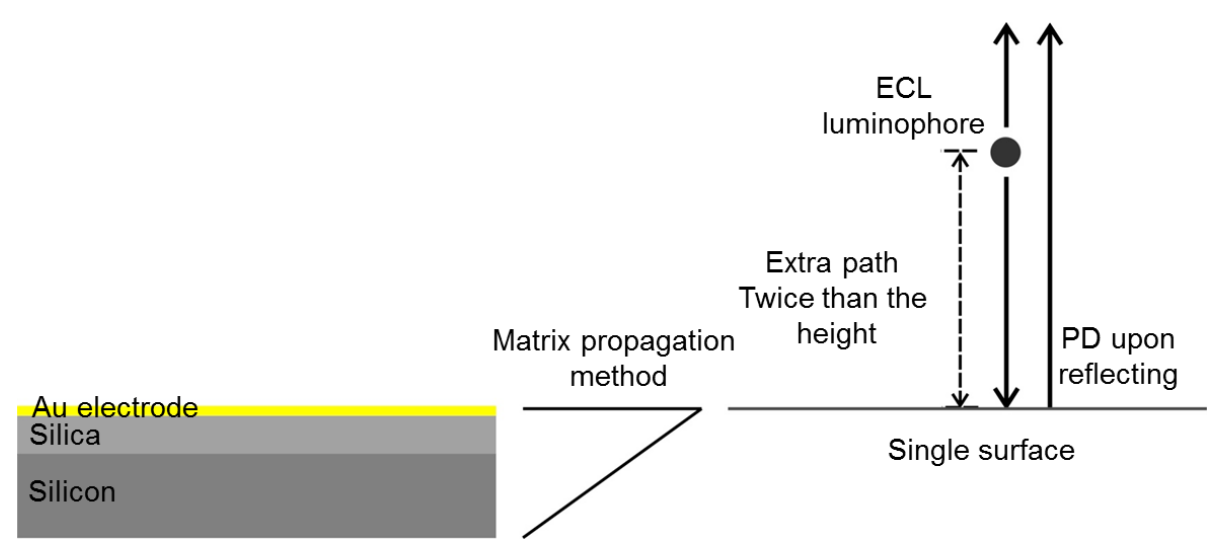

Figure S9. Schematic illustration of considering $\mathrm{ECL}$ reflection in the $\mathrm{Au} / \mathrm{SiO}_{2} / \mathrm{Si}$ electrode as that at a single surface by matrix propagation method. The phase difference between the two beams mainly consists of the extra optical path that the reflected light travels and the phase difference of reflected light caused by reflection at the interface. 


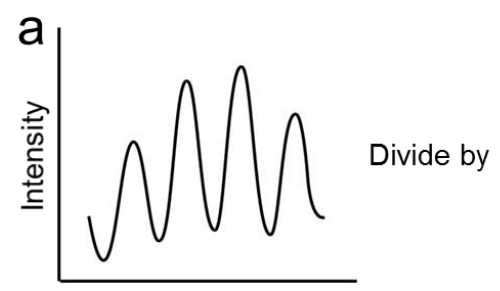

Wavelength

Measured ECLI spectrum b

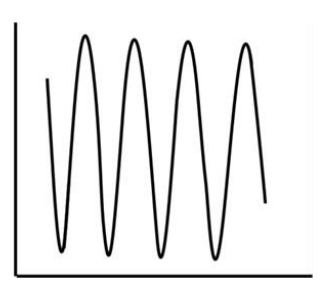

Wavelength

Interferometric components
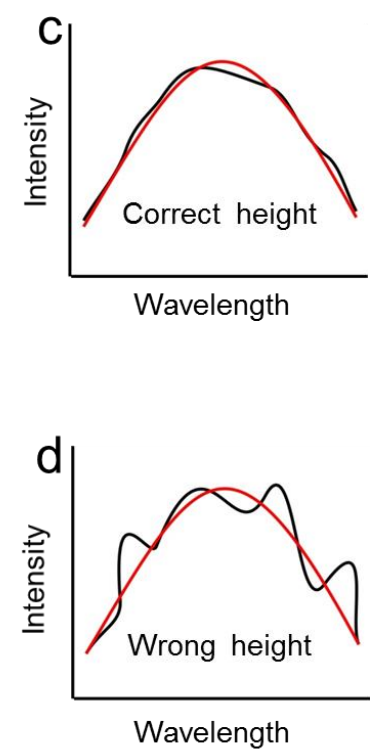

Resulting spectrum

Figure S10. Schematic illustration of fitting process for calculating the height of ECL luminophore from the electrode surface. (a) The measured ECLI spectrum with distinct oscillations. (b) Interferometric components calculated by eq. S18. (c, d) The resulting spectra with correct height (c) and wrong height (d) of ECL luminophores. The resulting spectrum was estimated by a 5-8 degree polynomial (red curves). A good matching indicates the correct height of the ECL luminophores.

However, the envelope of ECL, namely $I_{1}(\lambda)$, is difficult to measure precisely for the luminophore monolayer, because of low intensity of thus generated ECL (as shown in Figure S8). To solve this problem, an algorithm reported previously is used here. ${ }^{\text {S5-6 }}$ The experimental ECLI spectrum (Figure S10a) is divided by the calculated interferometric components (Figure S10b) to get the envelope of monolayer ECL, in which only the height of ECL luminophores is a variable. If the height is correct, the interferometric components will disappear, yielding a smooth curve akin to the normal ECL spectrum displayed by luminophore monolayer (Figure S10c, black curve). Otherwise, the resulting curve will still contain residual interferometric components (Figure S10d, black curve). A 5-8 degree polynomial was used for evaluating the smoothness of the resulting spectrum (Figure S10c and $\mathbf{d}$, red curves). The envelope of monolayer ECL without interference should be smooth with only one primary peak. The match does not have to be perfect, because only the deviation from a smooth curve caused by self-interference oscillations is measured. 
Note that all optical parameters related to the $\mathrm{Au} / \mathrm{SiO}_{2} / \mathrm{Si}$ electrode are known from ellipsometry and white light interferometric measurements. Using a minimum of leastsquares deviation as the criterion, the optimal matching between calculated and experimental spectra allowed the estimation of the height of ECL luminophores. The peaks ranging from $620 \mathrm{~nm}$ to $705 \mathrm{~nm}$ in ECLI spectrum are used to calculate the height.

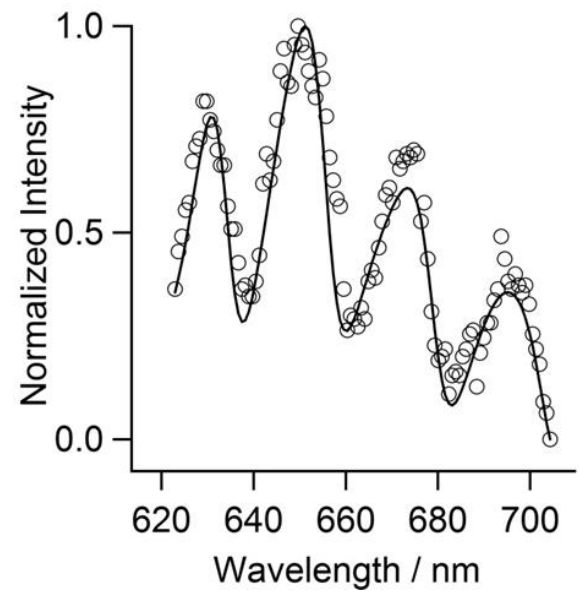

Figure S11. Experimental (open circles) and simulated (solid curves) monolayer ECLI spectra of $\mathrm{Au} / \mathrm{SiO}_{2} / \mathrm{Si}$ electrode modified with $\mathrm{Ru}(\mathrm{bpy})_{2}$ (apbpy) ${ }^{2+}$ via MPA in PB solution (0.2 M, pH 7.4) containing $30 \mathrm{mM}$ DBAE. The potential was swept from $0.6 \mathrm{~V}$ to $1.2 \mathrm{~V}$ and the scan rate was $0.05 \mathrm{~V} / \mathrm{s}$. Distinct and orderly distributed peaks are seen in the ECLI spectra, which are generated by the optical interference of ECL beam directly emitted by ECL luminophore and that reflected by the film electrode. The experimental and simulated ECLI spectra are close to each other, proving the validity of the theoretical model and the reliability of the calculated height of ECL luminophore.

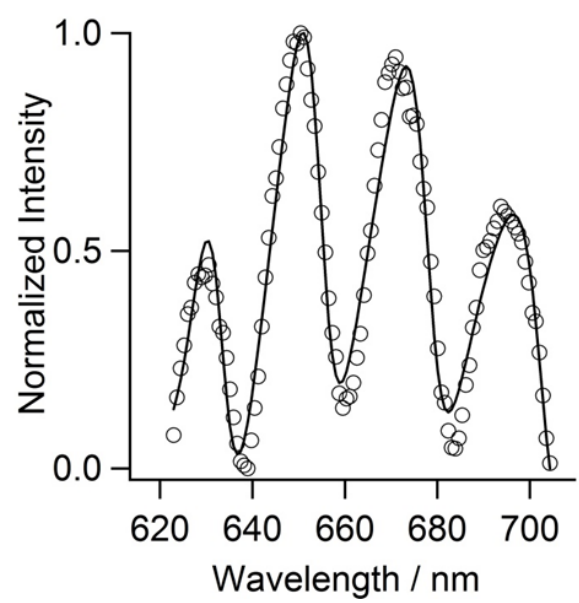

Figure S12. Experimental (open circles) and simulated (solid curves) monolayer ECLI spectra of $\mathrm{Au} / \mathrm{SiO}_{2} / \mathrm{Si}$ electrode modified with $\mathrm{Ru}(\mathrm{bpy})_{3}{ }^{2+}$ via 50 -bp double-stranded DNA in PB solution $(0.2 \mathrm{M}, \mathrm{pH} 7.4)$ containing $30 \mathrm{mM}$ DBAE. The potential was swept from $0.6 \mathrm{~V}$ to $1.2 \mathrm{~V}$ and the scan rate was $0.05 \mathrm{~V} / \mathrm{s}$. 


\section{S4. ECLI - Solution Phase}

\section{S4.1. Normal ECL Spectrum}

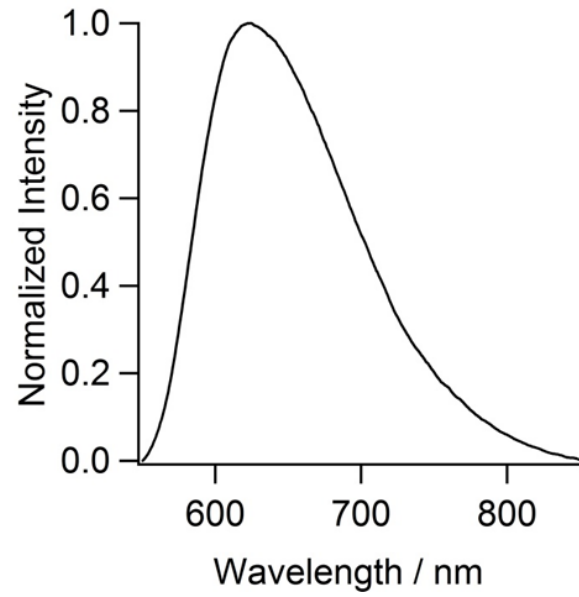

Figure S13. ECL spectrum of $\mathrm{Au}$ /glass electrode in PB solution (0.2 M, pH 7.4) containing $1 \mathrm{mM}$ $\mathrm{Ru}(\mathrm{bpy})_{3}{ }^{2+}$ and $30 \mathrm{mM}$ TPrA. The applied potential was $+1.2 \mathrm{~V}$.

\section{S4.2. Calculation by Matrix Propagation Model}

In the case of ECL generation at the electrode immersed in solutions containing $\mathrm{Ru}(\mathrm{bpy}) 3^{2+}$ and TPrA, the emissive excited states are distributed over a layer next to the electrode surface. The distance between them and the electrode surface varies, depending on the nature of co-reactant and the reaction pathway. In this case, there exists an ECL emitting layer with a certain thickness. This situation can be simplified by dividing the whole emitting layer into a certain number of sub-layers (as shown in Figure S14), each of which is then treated as a luminophore monolayer with a specific height. The phase difference caused by the reflection at the electrode is always the same (eq. S14), while the extra optical path that the reflected beam travels is varied for different sub-layers (eq. S1). In terms of eq. S18, the interferometric spectrum of each sub-layers can be calculated. Note that for multilayer ECLI, the envelope of ECL, namely $I_{1}(\lambda)$ was simply obtained by measuring the ECL spectrum of $A u / g$ lass electrode in solution containing $\mathrm{Ru}(\mathrm{bpy})_{3}{ }^{2+}$ and $\operatorname{TPrA}$. Furthermore, in order to consider the difference in the interference light intensity at different sub-layers, we also assume that there exists a linear concentration profile of emissive excited states, namely the 
concentration of emissive excited states decreases linearly from electrode surface to solution. Therefore, the summation of interferometric spectra generated by each sublayers will yield the ECLI spectrum. In the work, the thickness of sub-layers was set to $1 \mathrm{~nm}$. Using a minimum of least-squares deviation as the criterion, the optimal matching between calculated and experimental spectra allowed the estimation of the highest location of emissive excited states. This value is considered as the thickness of $E C L$ emitting layer. The peaks in the range of $600 \mathrm{~nm} \sim 690 \mathrm{~nm}$ in the ECLI spectrum are used for the calculation.

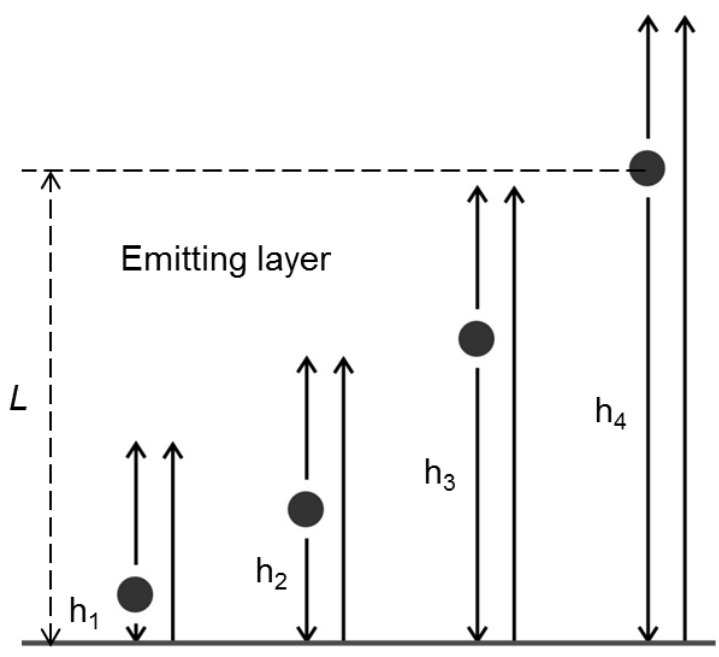

Figure S14. Schematic illustration of the model for calculating the ECLI spectrum in which the emitting layer is considered to consist of multiple sub-layers.
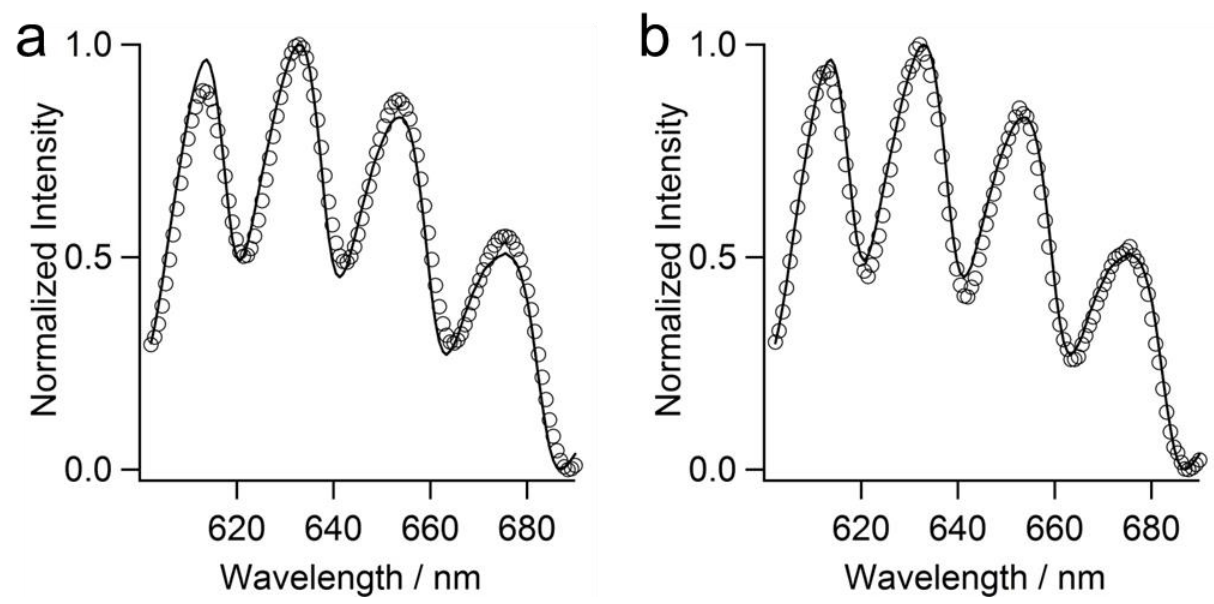

Figure S15. Experimental (open circles) and simulated (solid curves) multilayer ECLI spectra of $\mathrm{Au} / \mathrm{SiO}_{2} / \mathrm{Si}$ electrode in PB solution $(0.2 \mathrm{M}, \mathrm{pH} 7.4)$ containing $1 \mathrm{mM} \mathrm{Ru}(\mathrm{bpy})_{3}{ }^{2+} / 30 \mathrm{mM}$ TPrA (a) and $1 \mu \mathrm{M} \mathrm{Ru}(\mathrm{bpy})_{3}{ }^{2+} / 60 \mathrm{mM}$ TPrA (b). The applied potential was $+1.2 \mathrm{~V}$. 


\section{S4.3. ECL Reaction Pathways}

Taking TPrA as the co-reactant, we simply describe the production of emissive excited state of $\mathrm{Ru}(\mathrm{bpy})_{3}{ }^{2+}$ for $\mathrm{ECL}$ generation. At a sufficiently positive potential, both $\mathrm{Ru}(\mathrm{bpy})_{3}{ }^{2+}$ and TPrA can be directly oxidized at the electrode surface. So the emissive excited state can be generated by the homogeneous reduction of $\operatorname{Ru}($ bpy $) 3^{3+}$ by $\operatorname{TPr} A^{*}$ free radicals. The overall emitting process follows the classical "oxidative reduction" route involving steps, as shown in Figure $\mathbf{S 1 6}$ and $\mathbf{S 1 7}$. In dilute $\mathrm{Ru}(\mathrm{bpy})_{3}{ }^{2+}$ solutions $(<\sim \mu \mathrm{M})$ containing high concentration of TPrA (i.e., $60 \mathrm{mM})$, the emissive excited state can be also produced by the homogenous oxidation of $\mathrm{Ru}(\mathrm{bpy})_{3}{ }^{+}$by radical cation $\operatorname{TPrA}^{+\bullet}$ involving the steps shown in Figure $\mathbf{S 1 6} .^{\mathrm{S7}}$ Note that $\mathrm{TPrA}^{+\bullet}$ is a sufficiently stable intermediate with a half-lifetime of $\sim 0.2 \mathrm{~ms}^{58}$ At a high concentration of $\mathrm{Ru}(\mathrm{bpy}) 3^{2+}(\sim \mathrm{mM})$, the radical cation $\operatorname{TPrA}^{\bullet+}$ generated via oxidizing of TPrA by $\mathrm{Ru}(\mathrm{bpy}) 3^{3+}$ was also considerable (see Figure S17). ${ }^{\text {S9-10 }}$

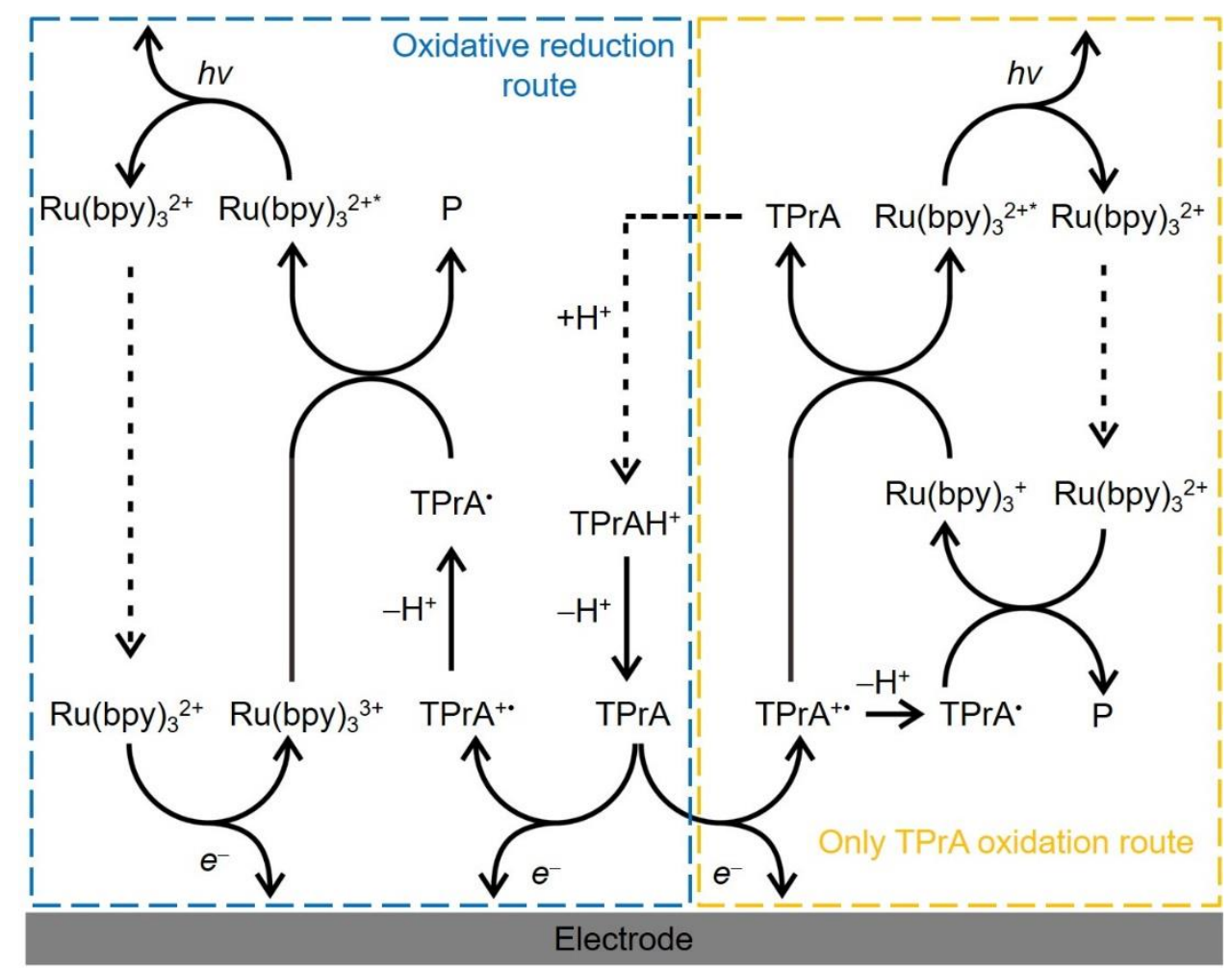

Figure S16. ECL reaction pathways of $\mathrm{Ru}(\mathrm{bpy})_{3}{ }^{2+} / \mathrm{TPrA}$ system at a low concentration of $\mathrm{Ru}(\mathrm{bpy})_{3}{ }^{2+}$. 


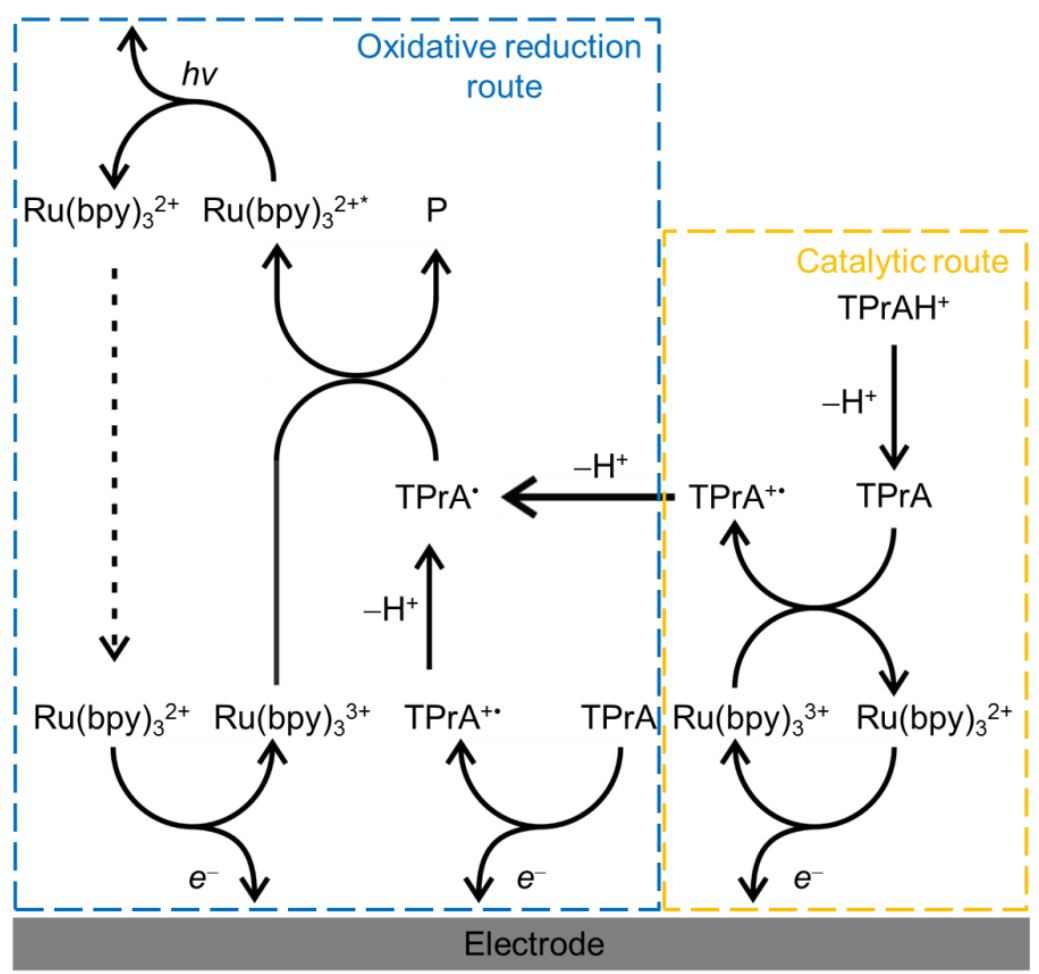

Figure S17. ECL reaction pathways of $\mathrm{Ru}(\mathrm{bpy})_{3}{ }^{2+} / \mathrm{TPrA}$ system at a high concentration of $\mathrm{Ru}(\mathrm{bpy})_{3}{ }^{2+}$.

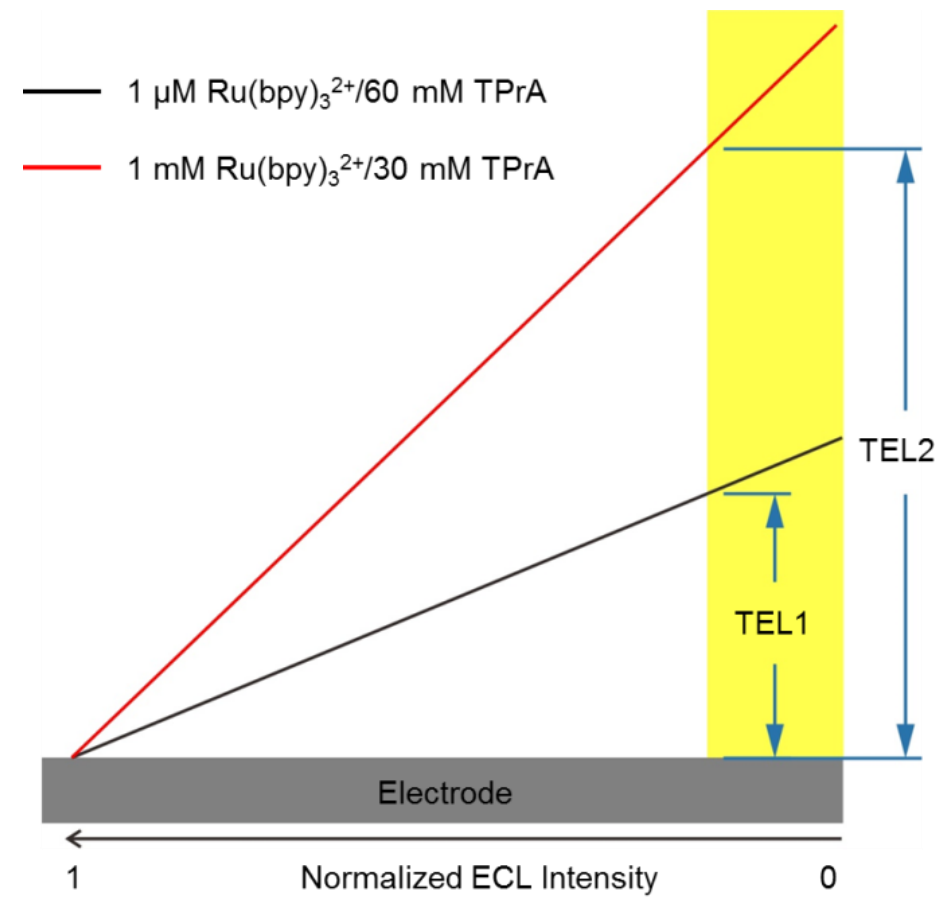

Figure S18. Illustration of the thickness of emitting layer (TEL) at a high (red curve) and low (black curve) concentration of $\mathrm{Ru}(\mathrm{bpy})_{3}{ }^{2+}$. The $\mathrm{ECL}$ intensity (concentration of $\mathrm{Ru}(\mathrm{bpy})_{3}{ }^{2+*}$ ) was assumed to decrease linearly at the direction normal to the electrode surface. The yellow region indicated that the $\mathrm{ECL}$ intensity was too weak to be detected. 


\section{S5. MATLAB-Code for Calculation}

\section{S5.1 White Light Interference}

Sentence after "\%" is annotation of the code. The refractive index data or experimental spectrum is "txt" file containing two or three columns.

$\mathrm{W}=\operatorname{load}($ 'C: $\backslash$ Users $\backslash$ Desktop $\backslash$ Calculation $\backslash A u N K . t x t ') ; \%$ Input refractive index of $\mathrm{Au}$ $\mathrm{K}=\operatorname{load}($ 'C: $\backslash$ Users $\backslash$ Desktop\Calculation\TiNK.txt');\%Input refractive index of Ti $\mathrm{N}=\operatorname{load}\left(\right.$ 'C: $\backslash$ Users $\backslash$ Desktop $\backslash$ Calculation $\backslash \mathrm{SiO} 2 \mathrm{NK} . t x t$ ');\%Input refractive index of $\mathrm{SiO}_{2}$

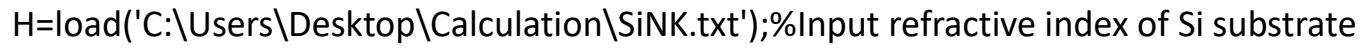
$\mathrm{T}=\operatorname{load}($ 'C: $\backslash$ Users $\backslash$ Desktop\Calculation\ECL envelope.txt');\%Input envelope of white light syms a1 n1 L1 a2 a3 L2 n2 L3 n3 n4

$\mathrm{X}=\mathrm{W}(:, 1) ; \%$ Wavelength

$Q_{n}=W(:, 2)$;

$\mathrm{Qk}=\mathrm{W}(:, 3)$;

$\mathrm{Rn}=\mathrm{K}(:, 2)$;

$\mathrm{Rk}=\mathrm{K}(:, 3)$;

$\mathrm{V}=\mathrm{N}(:, 2) ; \%$ Refractive index of $\mathrm{SiO}_{2}$

$\mathrm{Jn}=\mathrm{H}(:, 2)$;

$\mathrm{Jk}=\mathrm{H}(:, 3)$;

$\mathrm{Q}=\mathrm{Qn}-\mathrm{Qk} * 1 \mathrm{i} ; \%$ Refractive index of $\mathrm{Au}$

$\mathrm{R}=\mathrm{Rn}-\mathrm{Rk} * 1 \mathrm{i} ; \%$ Refractive index of $\mathrm{Ti}$

$\mathrm{J}=\mathrm{Jn}-\mathrm{Jk} * 1 \mathrm{i} ; \%$ Refractive index of $\mathrm{Si}$

$\mathrm{T} 1=\mathrm{T}(:, 2) ; \%$ Envelope of white light

$\mathrm{n} 0=1 ; \%$ Refractive index of air

aa $=1 ; \%$ Count cycling numbers

L1=11.8;\%Thickness of Au layer

$\mathrm{L} 2=4.65 ; \%$ Thickness of $\mathrm{Ti}$ layer

$\mathrm{L} 3=$ start:interval:final;\%Range of the thickness of $\mathrm{SiO}_{2}$ layer. "interval" means the interval between the values of thickness used in calculation.

U $=\operatorname{load}($ 'C: $\backslash$ Users $\backslash$ Desktop \Calculation $\backslash W L$ experimental.txt');\%Input experimental white light interference spectrum

$\mathrm{Ux}=\mathrm{U}(:, 1)$;

$\mathrm{Uy}=\mathrm{U}(:, 2)$;

$\mathrm{U} 1=\max (\mathrm{Uy})$;

$\mathrm{U} 2=\min (\mathrm{Uy})$;

U3 $=(U y-U 2) /(U 1-U 2) ; \%$ Normalize experimental white light interference spectrum $\mathrm{dd}=$ length(L1)*length(L2)*length(L3);

CL1=zeros(dd,1);

$\mathrm{CL2}=$ zeros(dd,1);

$\mathrm{CL} 3=z e r o s(d d, 1)$;

FINA=zeros(dd,1);

$c c=$ length $(X)$;

for $\mathrm{a} 0=1$ :length $(\mathrm{L} 1)$ 
for $b 0=1$ :length (L2)

for $\mathrm{C} 0=1$ :length(L3)

$\mathrm{L} 11=\mathrm{L} 1(:, \mathrm{a} 0)$;

$\mathrm{L} 22=\mathrm{L} 2(:, \mathrm{b} 0)$;

$\mathrm{L} 33=\mathrm{L} 3(:, \mathrm{CO})$;

$M=z e r o s(c c, 1)$;

for $i=1: c c$

$\mathrm{n} 1=\mathrm{Q}(\mathrm{i}, \mathrm{:}) ;$

$\mathrm{n} 2=\mathrm{R}(\mathrm{i}, \mathrm{:})$;

$n 3=V(i,:)$;

n4=J(i,:);

$\mathrm{Tn}=\mathrm{T} 1(\mathrm{i}, \mathrm{:})$;

$p=X(i,:)$;

a1 $=\left(2 * p^{*}{ }^{*}\right.$ n $*$ L11) $) / p$;

a2 $=\left(2 * p^{*}{ }^{*} 2 * L 22\right) / p$;

a3 $=\left(2 * p^{*}{ }^{*} 3 *\right.$ L33 $) / p$;

$A=\left[\cos (a 1)\left(1 i^{*} \sin (a 1)\right) / n 1 ; 1 i^{*} n 1 * \sin (a 1) \cos (a 1)\right] ; \%$ Matrix Propagation Methd

$\mathrm{B}=[\cos (\mathrm{a} 2)(1 \mathrm{i} * \sin (\mathrm{a} 2)) / \mathrm{n} 2 ; 1 \mathrm{i} * \mathrm{n} 2 * \sin (\mathrm{a} 2) \cos (\mathrm{a} 2)] ; \%$ Matrix Propagation Methd

$\mathrm{C}=\left[\cos (\mathrm{a} 3)\left(1 i^{*} \sin (\mathrm{a} 3)\right) / \mathrm{n} 3 ; 1 i^{*} \mathrm{n} 3 * \sin (\mathrm{a} 3) \cos (\mathrm{a} 3)\right] ; \%$ Matrix Propagation Methd

$\mathrm{D}=[1 ; \mathrm{n} 4] ; \%$ Matrix Propagation Methd

$E=A * B * C * D ; \%$ Matrix Propagation Methd

$\mathrm{F}=\mathrm{E}(1, \mathrm{:}) ; \%$ Matrix Propagation Methd

$\mathrm{G}=\mathrm{E}(2,:) ; \%$ Matrix Propagation Methd

$\mathrm{H} 1=((\mathrm{nO}) * \mathrm{~F}-\mathrm{G}) /((\mathrm{nO}) * \mathrm{~F}+\mathrm{G})$;

$\mathrm{H} 2=\operatorname{conj}(\mathrm{H} 1)$;

$\mathrm{H} 3=(\mathrm{H} 1) *(\mathrm{H} 2) ; \%$ Reflectance of the electrode

$\mathrm{H} 4=\mathrm{H} 3 * \mathrm{Tn} ; \%$ eq S16

$\mathrm{M}(\mathrm{i})=\mathrm{H} 4$;

end

$\mathrm{M} 1=\max (\mathrm{M})$;

$\mathrm{M} 2=\min (\mathrm{M})$;

$M 3=(M-M 2) /(M 1-M 2) ; \%$ Normalize theoretical white light interference spectrum

$\mathrm{X} 2=\mathrm{M} 3-\mathrm{U} 3$

$\mathrm{X} 3=\mathrm{X} 2 .^{\wedge} 2$;

$\mathrm{XF}=\operatorname{sum}(\mathrm{X} 3)$;

$\mathrm{CL1}(\mathrm{aa})=\mathrm{L} 11$;

$\mathrm{CL} 2(\mathrm{aa})=\mathrm{L} 22$;

$\mathrm{CL} 3(\mathrm{aa})=\mathrm{L} 33$;

$\mathrm{FINA}(\mathrm{aa})=\mathrm{XF} ; \%$ Record deviation

$\mathrm{aa}=\mathrm{aa}+1$;

end

end

end

[minx,ind $]=\min (\mathrm{FINA}) \%$ Using a minimum of least-squares deviation as the criterion 
$\mathrm{L} 3 \mathrm{~F}=\mathrm{CL} 3($ ind)\%Thickness of silica layer

\section{S5.2 ECLI - Luminophore Monolayer}

$W=\operatorname{load}(' C: \backslash$ Users $\backslash$ Desktop $\backslash$ Calculation $\backslash A u N K . t x t ') ; \%$ Input refractive index of $\mathrm{Au}$ $\mathrm{K}=\operatorname{load}\left({ }^{\prime} \mathrm{C}: \backslash\right.$ Users $\backslash$ Desktop $\backslash$ Calculation $\left.\backslash T i N K . t x t '\right) ; \%$ Input refractive index of Ti $\mathrm{N}=$ load('C:〈Users\Desktop\Calculation \SiO2NK.txt');\%Input refractive index of $\mathrm{SiO}_{2}$ $\mathrm{H}=\operatorname{load}\left({ }^{\prime} \mathrm{C}: \backslash\right.$ Users $\backslash$ Desktop $\backslash$ Calculation $\left.\backslash S i N K . t x t '\right) ; \%$ Input refractive index of Si substrate syms a1 n1 L1 a2 a3 L2 n2 L3 n3 n4

$\mathrm{X}=\mathrm{W}(:, 1) ; \%$ Wavelength

$\mathrm{Qn}=\mathrm{W}(:, 2)$;

$\mathrm{Qk}=\mathrm{W}(:, 3)$;

$\mathrm{Rn}=\mathrm{K}(:, 2)$;

$\mathrm{Rk}=\mathrm{K}(:, 3)$;

$\mathrm{V}=\mathrm{N}(:, 2) ; \%$ Refractive index of $\mathrm{SiO}_{2}$

$\mathrm{Jn}=\mathrm{H}(:, 2)$;

$\mathrm{Jk}=\mathrm{H}(:, 3)$;

$\mathrm{Q}=\mathrm{Qn}-\mathrm{Qk} * 1 \mathrm{i} ; \%$ Refractive index of $\mathrm{Au}$

$\mathrm{R}=\mathrm{Rn}-\mathrm{Rk} * 1 \mathrm{i} ; \%$ Refractive index of $\mathrm{Ti}$

$\mathrm{J}=\mathrm{Jn}-\mathrm{Jk} * 1 \mathrm{i} ; \%$ Refractive index of $\mathrm{Si}$

$\mathrm{n} 0=1.3375 ; \%$ Refractive index of solution

aa $=1 ; \%$ Count cycling numbers

L1=11.8;\%Thickness of Au layer

$\mathrm{L} 2=4.65 ; \%$ Thickness of Ti layer

L3 $=\quad ; \%$ Thickness of silica layer, calculated by white light interference.

DIS= start:interval:final;\%Range of the height. "interval" means the interval between the values of height used in calculation.

$\mathrm{U}=\operatorname{load}($ 'C: $\backslash$ Users \Desktop\Calculation\ECLI experimental.txt');\%Input experimental ECLI spectrum

$\mathrm{Ux}=\mathrm{U}(:, 1)$;

$\mathrm{Uy}=\mathrm{U}(:, 2)$;

$\mathrm{dd}=$ length(L1)*length(L2)*length(L3)*length(DIS);

$\mathrm{CL1}=$ zeros$(\mathrm{dd}, 1)$;

$\mathrm{CL2}=$ zeros $(\mathrm{dd}, 1)$;

$\mathrm{CL3}=$ zeros $(\mathrm{dd}, 1)$;

$\mathrm{DL}=$ zeros(dd,1);

FINA=zeros(dd,1);

for $\mathrm{a} 0=1$ :length $(\mathrm{L} 1)$

for b0 $=1$ :length(L2)

for $\mathrm{C} 0=1$ :length $(\mathrm{L} 3)$

for $\mathrm{d} 0=1$ :length(DIS)

$\mathrm{L} 11=\mathrm{L} 1(:, \mathrm{a} 0)$;

$\mathrm{L} 22=\mathrm{L} 2(:, \mathrm{b0})$;

L33=L3(:,C0);

DECL=DIS(:,d0); 


$$
M=z e r o s(108,1) \text {; }
$$

for $i=1: 108 \% " 108 "$ is the number of points consisting a spectrum

$\mathrm{n} 1=\mathrm{Q}(\mathrm{i}, \mathrm{:})$;

$\mathrm{n} 2=\mathrm{R}(\mathrm{i}, \mathrm{:})$;

$\mathrm{n} 3=\mathrm{V}(\mathrm{i}, \mathrm{:})$;

$\mathrm{n} 4=\mathrm{J}(\mathrm{i}, \mathrm{:})$;

$$
p=X(i,:) ;
$$

a1 $=\left(2 * \mathrm{pi}^{*} \mathrm{n} 1 * \mathrm{~L} 11\right) / \mathrm{p}$;

$\mathrm{a} 2=(2 * \mathrm{pi} * \mathrm{n} 2 * \mathrm{~L} 22) / \mathrm{p}$;

a3 $=\left(2 * \mathrm{pi}^{*} \mathrm{n} 3 * \mathrm{L3}\right) / \mathrm{p}$;

$A=\left[\cos (a 1)\left(1 i^{*} \sin (a 1)\right) / n 1 ; 1 i^{*} n 1 * \sin (a 1) \cos (a 1)\right] ; \%$ Matrix Propagation Methd

$B=\left[\cos (a 2)(1 i * \sin (a 2)) / n 2 ; 1 i^{*} n 2 * \sin (a 2) \cos (a 2)\right] ; \%$ Matrix Propagation Methd

$\mathrm{C}=\left[\cos (\mathrm{a} 3)\left(1 i^{*} \sin (\mathrm{a} 3)\right) / \mathrm{n3} ; 1 i^{*} \mathrm{n} 3 * \sin (\mathrm{a} 3) \cos (\mathrm{a} 3)\right] ; \%$ Matrix Propagation Methd

$\mathrm{D}=[1 ; \mathrm{n} 4] ; \%$ Matrix Propagation Methd

$\mathrm{E}=\mathrm{A} * \mathrm{~B} * \mathrm{C} * \mathrm{D} ; \%$ Matrix Propagation Methd

$\mathrm{F}=\mathrm{E}(1, \mathrm{:}) ; \%$ Matrix Propagation Methd

$\mathrm{G}=\mathrm{E}(2, \mathrm{)}) ; \%$ Matrix Propagation Methd

$\mathrm{F} 1=\operatorname{conj}(\mathrm{F})$;

$\mathrm{G} 1=\operatorname{conj}(\mathrm{G})$;

$\mathrm{H} 1=((\mathrm{n} 0) * \mathrm{~F}-\mathrm{G}) /((\mathrm{n} 0) * \mathrm{~F}+\mathrm{G})$;

$\mathrm{H} 2=\operatorname{conj}(\mathrm{H} 1)$;

$\mathrm{H} 3=(\mathrm{H} 1) *(\mathrm{H} 2) ; \%$ Reflectance of the electrode

pha1=atan $\left(\left(1 i^{*} 0^{*}(G * F 1-F * G 1)\right) /\left(n 0^{\wedge} 2 * F * F 1-G * G 1\right)\right) ; \%$ Phase difference due to reflection at the front interface

$11=1$;

$12=11 * \mathrm{H} 3$;

Pha $=$ pha1-4*pi*(1.3375*DECL)/p;\%Total phase difference between the two ECL beams $\mathrm{I}=\mathrm{I} 1+12+\left(2 *\left(I 1^{*} \mid 2\right)^{\wedge} 0.5\right)^{*} \cos (\mathrm{Pha}) ; \%$ Interferometric components

$M(i)=1 ;$

end

$\mathrm{X} 2=\mathrm{Uy} . / \mathrm{M} ; \%$ Depicted by Figure S10

$\%$ Curving Fitting, Depicted by Figure S10

[xData, $\mathrm{yData}]=$ prepareCurveData $(\mathrm{X}, \mathrm{X} 2)$;

$\%$ Set up fittype and options.

$\mathrm{ft}=$ fittype( 'poly8' );

[fitresult, gof] = fit $(x D a t a, y$ Data, $f t)$;

$\mathrm{XF}=$ cat $(1$, gof.sse);

$\mathrm{CL1}(\mathrm{aa})=\mathrm{L} 11$;

$\mathrm{CL} 2(\mathrm{aa})=\mathrm{L} 22$;

$\mathrm{CL} 3(\mathrm{aa})=\mathrm{L} 33$;

$\mathrm{DL}(\mathrm{aa})=\mathrm{DECL}$;

FINA(aa) $=X F ; \%$ Record deviation, depicted by Figure $\mathbf{S 1 0}$

$a a=a a+1$;

end 


$$
\text { end }
$$

end

end

[minx,ind] $=\min (\mathrm{FINA}) \%$ Using a minimum of least-squares deviation as the criterion $\mathrm{DLF}=\mathrm{DL}$ (ind)\%Height of ECL luminophore

\section{S5.3 ECLI - Solution Phase}

$W=\operatorname{load}(' C: \backslash$ Users $\backslash$ Desktop $\backslash$ Calculation $\backslash A u N K . t x t ') ; \%$ Input refractive index of $\mathrm{Au}$ $\mathrm{K}=$ load('C: $\backslash$ Users $\backslash$ Desktop $\backslash$ Calculation $\backslash T i N K . t x t ') ; \%$ Input refractive index of Ti $\mathrm{N}=\operatorname{load}\left(\mathrm{C}^{\mathrm{C}} \backslash\right.$ Users $\backslash$ Desktop $\backslash$ Calculation\SiO2NK.txt');\%Input refractive index of $\mathrm{SiO}_{2}$ $\mathrm{H}=\operatorname{load}($ 'C: $\backslash$ Users $\backslash$ Desktop $\backslash$ Calculation\SiNK.txt'); \% Input refractive index of Si substrate $\mathrm{T}=\operatorname{load}\left({ }^{\prime} \mathrm{C}: \backslash\right.$ Users $\backslash$ Desktop $\backslash$ Calculation $\backslash E C L$ envelope.txt');\%Input envelope of ECL $\mathrm{U}=\operatorname{load}($ 'C: $\backslash$ Users \Desktop\Calculation\ECLI experimental.txt');\%Input experimental ECLI spectrum

$\mathrm{Ux}=\mathrm{U}(:, 1)$;

$\mathrm{Uy}=\mathrm{U}(:, 2)$;

$\mathrm{U} 1=\max (\mathrm{Uy})$;

$\mathrm{U} 2=\min (U y)$;

U3=(Uy-U2)/(U1-U2);\%Normalize experimental ECLI spectrum syms n0 a1 n1 I1 a2 I2 n2 n3 n4

$\mathrm{X}=\mathrm{W}(:, 1) ; \%$ Wavelength

$\mathrm{Qn}_{\mathrm{n}}=\mathrm{W}(:, 2)$;

$\mathrm{Qk}=\mathrm{W}(:, 3)$;

$\mathrm{Rn}=\mathrm{K}(:, 2)$;

$\mathrm{Rk}=\mathrm{K}(:, 3)$;

$\mathrm{V}=\mathrm{N}(:, 2) ; \%$ Refractive index of $\mathrm{SiO}_{2}$

$\mathrm{Jn}=\mathrm{H}(:, 2)$;

$\mathrm{Jk}=\mathrm{H}(:, 3)$;

$\mathrm{Q}=\mathrm{Qn}-\mathrm{Qk} * 1 \mathrm{i} ; \%$ Refractive index of $\mathrm{Au}$

$\mathrm{R}=\mathrm{Rn}-\mathrm{Rk} * 1 \mathrm{i} ; \%$ Refractive index of $\mathrm{Ti}$

$\mathrm{J}=\mathrm{Jn}-\mathrm{Jk} * 1 \mathrm{i} ; \%$ Refractive index of $\mathrm{Si}$

$\mathrm{T} 1=\mathrm{T}(:, 2) ; \%$ Envelope of $\mathrm{ECL}$

$\mathrm{n} 0=1.3375 ; \%$ Refractive index of solution

aa $=1 ; \%$ Count cycling numbers

I1=11.8; \% Thickness of Au layer

12=4.65; \% Thickness of Ti layer

$13=\quad ; \%$ Thickness of $\mathrm{SiO}_{2}$ layer, calculated by white light interference.

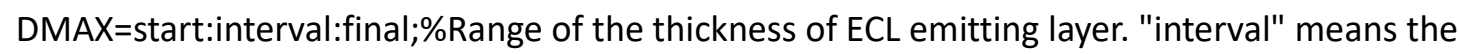
interval between the values of thickness used in calculation.

$c c=$ length $(X)$;

dd=length(DMAX)*length(I3);

FINA=zeros $(d d, 1)$;

$\mathrm{CL} 3=$ zeros $(\mathrm{dd}, 1)$;

CLL=zeros(dd,1); 
$\mathrm{M}=\mathrm{zeros}(\mathrm{cc}, 1)$;

$\mathrm{MX}=\mathrm{zeros}(\mathrm{cc}, 1)$;

for b0=1:length(I3);

$\mathrm{L} 33=13(:, \mathrm{bO})$;

for $\mathrm{a} 0=1$ :length(DMAX);

DMAX1=DMAX(:,a0);

$D E C L=1: 1: D M A X 1 ; \% D i v i d e$ the $E C L$ emitting layer into a number of sub-layers with thickness of $1 \mathrm{~nm}$.

$k k=1 /($ length $(D E C L))$;

for $\mathrm{C} 0=1$ :length $(\mathrm{DECL})$

$\mathrm{LL}=\mathrm{DECL}(:, \mathrm{C} 0)$;

ratio $=1-(\mathrm{c} 0-1)^{*} \mathrm{kk} ; \%$ Linear distribution profile of $\mathrm{Ru}(\mathrm{bpy})_{3}{ }^{2+*}$

$\mathrm{M}=\mathrm{zeros}(\mathrm{cc}, 1)$

for $i=1$ :cc

$\mathrm{n} 1=\mathrm{Q}(\mathrm{i}, \mathrm{:})$;

$\mathrm{n} 2=\mathrm{R}(\mathrm{i}, \mathrm{:})$;

$\mathrm{n} 3=\mathrm{V}(\mathrm{i}, \mathrm{i})$;

$\mathrm{n} 4=\mathrm{J}(\mathrm{i}, \mathrm{i})$;

$\mathrm{Tn}=\mathrm{T} 1(\mathrm{i},:)$;

$\mathrm{p}=\mathrm{X}(\mathrm{i}, \mathrm{i})$;

a1 $=\left(2 * \mathrm{pi}^{*} \mathrm{n} 1 * \mid 1\right) / \mathrm{p}$;

a2 $=(2 * \mathrm{pi} * \mathrm{n} 2 * 12) / \mathrm{p}$;

a3 $=(2 * \mathrm{pi} * \mathrm{n} 3 * \mathrm{L3} 3) / \mathrm{p}$;

$A=\left[\cos (a 1)\left(1 i^{*} \sin (a 1)\right) / n 1 ; 1 i^{*} n 1 * \sin (a 1) \cos (a 1)\right] ; \%$ Matrix Propagation Methd

$\mathrm{B}=\left[\cos (\mathrm{a} 2)\left(1 i^{*} \sin (\mathrm{a} 2)\right) / \mathrm{n} 2 ; 1 i^{*} n 2 * \sin (\mathrm{a} 2) \cos (\mathrm{a} 2)\right] ; \%$ Matrix Propagation Methd

$\mathrm{C}=\left[\cos (\mathrm{a} 3)\left(1 \mathrm{i}^{*} \sin (\mathrm{a} 3)\right) / \mathrm{n} 3 ; 1 \mathrm{i}^{*} \mathrm{n} 3 * \sin (\mathrm{a} 3) \cos (\mathrm{a} 3)\right] ; \%$ Matrix Propagation Methd

$\mathrm{D}=[1 ; \mathrm{n} 4] ; \%$ Matrix Propagation Methd

$\mathrm{E}=\mathrm{A}^{*} \mathrm{~B} \mathrm{C}^{*} \mathrm{D} ; \%$ Matrix Propagation Methd

$\mathrm{F}=\mathrm{E}(1, \mathrm{)}) ; \%$ Matrix Propagation Methd

$\mathrm{G}=\mathrm{E}(2,:) ; \%$ Matrix Propagation Methd

$\mathrm{F} 1=\operatorname{conj}(\mathrm{F})$;

$\mathrm{G} 1=\operatorname{conj}(\mathrm{G})$;

$\mathrm{H} 1=((\mathrm{nO}) * \mathrm{~F}-\mathrm{G}) /((\mathrm{n} 0) * \mathrm{~F}+\mathrm{G})$;

$\mathrm{H} 2=\operatorname{conj}(\mathrm{H} 1)$;

$\mathrm{H} 3=(\mathrm{H} 1) *(\mathrm{H} 2) ; \%$ Reflectance of the electrode

pha1 $=\operatorname{atan}\left(\left(1 i^{*} n 0^{*}\left(G^{*} F 1-F^{*} G 1\right)\right) /\left(n 0^{\wedge} 2 * F * F 1-G * G 1\right)\right) ; \%$ Phase difference due to reflection at the front interface

II=Tn;

$12=11 * \mathrm{H} 3$;

Pha=pha1- $4^{*} \mathrm{pi}^{*}\left(1.3375^{*} \mathrm{LL}\right) / \mathrm{p} ; \%$ Total phase difference between the two ECL beams

$I=I 1+12+\left(2 *(I 1 * 12)^{\wedge} 0.5\right)^{*} \cos ($ Pha $) ; \%$ eq S18

$M(i)=1$;

end

$M=$ ratio* $M ; \%$ Linear distribution profile of $R u(b p y) 3_{3}{ }^{2+*}$ 
$M X=M X+M ;$

end

$\mathrm{M} 1=\max (\mathrm{MX})$;

$\mathrm{M} 2=\min (\mathrm{MX})$;

M3=(MX-M2)/(M1-M2);\%Normalize theoretical ECLI spectrum

$\mathrm{X} 2=\mathrm{U} 3-\mathrm{M} 3$;

$\mathrm{X} 3=\mathrm{X} 2 .^{\wedge} 2$;

$\mathrm{XF}=\operatorname{sum}(\mathrm{X} 3) ; \% \mathrm{Using}$ a minimum of least-squares deviation as the criterion

$\mathrm{CL} 3(\mathrm{aa})=\mathrm{L} 33$;

$\mathrm{CLL}(\mathrm{aa})=\mathrm{DMAX} 1$

FINA(aa) $=X F$;

$\mathrm{aa}=\mathrm{aa}+1$;

$\mathrm{MX}=\mathrm{zeros}(\mathrm{cc}, 1)$;

end

end

[minx,ind $]=\min ($ FINA)\%Using a minimum of least-squares deviation as the criterion

DLF=CLL(ind)\%Thickness of emitting layer 


\section{References}

(S1) Johansson, O.; Borgstrom, M.; Lomoth, R.; Palmblad, M.; Bergquist, J.; Hammarstrom, L.; Sun, L. C.; Akermark, B. Electron Donor-Acceptor Dyads Based on Ruthenium(II) Bipyridine and Terpyridine Complexes Bound to Naphthalenediimide. Inorg. Chem. 2003, 42, 2908-2918.

(S2) Jousselme, B.; Bidan, G.; Billon, M.; Goyer, C.; Kervella, Y.; Guillerez, S.; Hamad, E. A.; GozeBac, C.; Mevellec, J.-Y.; Lefrant, S. One-Step Electrochemical Modification of Carbon Nanotubes by Ruthenium Complexes via New Diazonium Salts. J. Electroanal. Chem. 2008, 621, 277-285.

(S3) Guo, W. L.; Cao, Z. Y.; Liu, Y. H.; Su, B. Electrochemiluminescence of a Vinyl-Functionalized Ruthenium Complex and Its Monolayer Formed through the Photoinduced Thiol-Ene Click Reaction. Chemelectrochem 2017, 4, 1763-1767.

(S4) Macleod, H. A. Thin-Film Optical Filters. CRC press: 2010.

(S5) Moiseev, L.; Cantor, C. R.; Swan, A. K.; Goldberg, B. B.; Uelue, M. S. Biological Applications of Spectral Self-Interference. Proc. SPIE-Int. Soc. Opt. Eng. 2004, 5331, 36-43.

(S6) Moiseev, L.; Cantor, C. R.; Aksun, M. I.; Dogan, M.; Goldberg, B. B.; Swan, A. K.; Unlu, M. S., Spectral Self-Interference Fluorescence Microscopy. J. Appl. Phys. 2004, 96, 5311-5315.

(S7) Hu, L.; Xu, G. Applications and Trends in Electrochemiluminescence. Chem. Soc. Rev. 2010, 39, 3275-3304.

(S8) Miao, W.; Choi, J.-P.; Bard, A. J. Electrogenerated Chemiluminescence 69: The Tris(2,2'bipyridine)ruthenium(II), ( $\left.\mathrm{Ru}(\mathrm{bpy})_{3}{ }^{2+}\right) /$ tri-n-propylamine (TPrA) System Revisited-A New Route Involving TPrA ${ }^{*+}$ Cation Radicals. J. Am. Chem. Soc. 2002, 124, 14478-14485.

(S9) Zu, Y.; Bard, A. J. Electrogenerated Chemiluminescence. 66. The Role of Direct Coreactant Oxidation in the Ruthenium Tris(2,2')bipyridyl/tripropylamine System and the Effect of Halide Ions on the Emission Intensity. Anal. Chem. 2000, 72, 3223-3232.

(S10) Chovin, A.; Garrigue, P.; Vinatier, P.; Sojic, N., Development of an Ordered Array of Optoelectrochemical Individually Readable Sensors with Submicrometer Dimensions: Application to Remote Electrochemiluminescence Imaging. Anal. Chem. 2004, 76, 357-364. 